\title{
Coupled hydraulic-mechanical simulation of seasonally induced processes in the Mont Terri rock laboratory (Switzerland)
}

\author{
Gesa Ziefle $^{1}\left(\mathbb{D} \cdot\right.$ Jean-Michel Matray $^{2} \cdot$ Jobst Maßmann $^{1} \cdot$ Andreas Möri $^{3}$
}

Received: 3 March 2016/Accepted: 9 December 2016/Published online: 17 February 2017

(C) The Author(s) 2017. This article is published with open access at Springerlink.com

\begin{abstract}
This paper focuses on hydraulic-mechanical effects in the Mont Terri rock laboratory (Switzerland) and investigates their impact on pore pressure, the convergence of a niche and the evolution of pre-existing cracks in the wallrock of the niche. A comparison of measurements with numerical simulation results is conducted. The presented in situ measurements include long-term data on temperature, relative humidity, and niche convergence, as well as crackmeter and jointmeter measurements determining the aperture of a bedding-parallel crack. Furthermore, timedomain-reflectometry measurements were carried out in a borehole located in the niche wall close to the crack. They provide information on the water content of the claystone. The numerical simulation is carried out with OpenGeoSys. It contains a 2-dimensional coupled hydraulic-mechanical model considering orthotropy, swelling and shrinkage effects, linear elastic material behaviour and an excavation damaged zone characterized by a zone of lower rock strength. An additional focus is laid on the evolution of cracks in the wallrock of the niche. The presented model approach allows a prediction of the temporal evolution of a
\end{abstract}

Editorial handling: P. Bossart and A. G. Milnes.

This is paper \#9 of the Mont Terri Special Issue of the Swiss Journal of Geosciences (see Bossart et al. (2017), Table 3 and Fig. 7).

Gesa Ziefle

gesa.ziefle@bgr.de

1 Federal Institute for Geosciences and Natural Resources (BGR), Stilleweg 2, 30655 Hannover, Germany

2 Institut de Radioprotection et de Surete Nucleaire, BP 17, 92262 Fontenay-aux-Roses Cedex, France

3 Federal Office of Topography Swisstopo, Seftigenstrasse 264, 3084 Wabern, Switzerland desaturated zone incorporating a seasonally influenced part. The comparison with measured water contents yields good agreement. Simulation results and measurements consistently predict a convergence of the niche. The evolution of the crack aperture is influenced by long-term as well as seasonallyinfluenced effects. Due to the convergence of the niche, the long-term trend is characterized by closure of the crack. Furthermore, the seasonally influenced desaturation in winter results in opening of the crack, while the resaturation in the warm and wet summer months leads to closure of the crack. Finally, the comparison of simulation results with measurements indicates qualitative agreement. As a matter of fact, the numerical model seems to represent significant effects concerning the evolution of the crack aperture of a single crack.

Keywords Cyclic deformation (CD) experiment · Longterm monitoring of pore parameters (LP-A) experiment . OpenGeoSys - Desaturation process - Atmospheric influences · Crack evolution · Nuclear waste disposal

\section{Introduction}

This article is based on the $\mathrm{CD}$ (cyclic deformation) experiment which is carried out in the Mont Terri rock laboratory, located in the Opalinus Clay formation in Switzerland. Figure 1 presents the cross section through the Mont Terri anticline and the location of the rock laboratory. The $\mathrm{CD}$ experiment is located in the EZB-niche of the underground laboratory (see Bossart et al. 2017). It focuses on the seasonally induced hydraulic-mechanical coupling at the wallrock of the uncovered niche in the claystone. In this context, the investigations focus on the desaturation and resaturation process, swelling and 


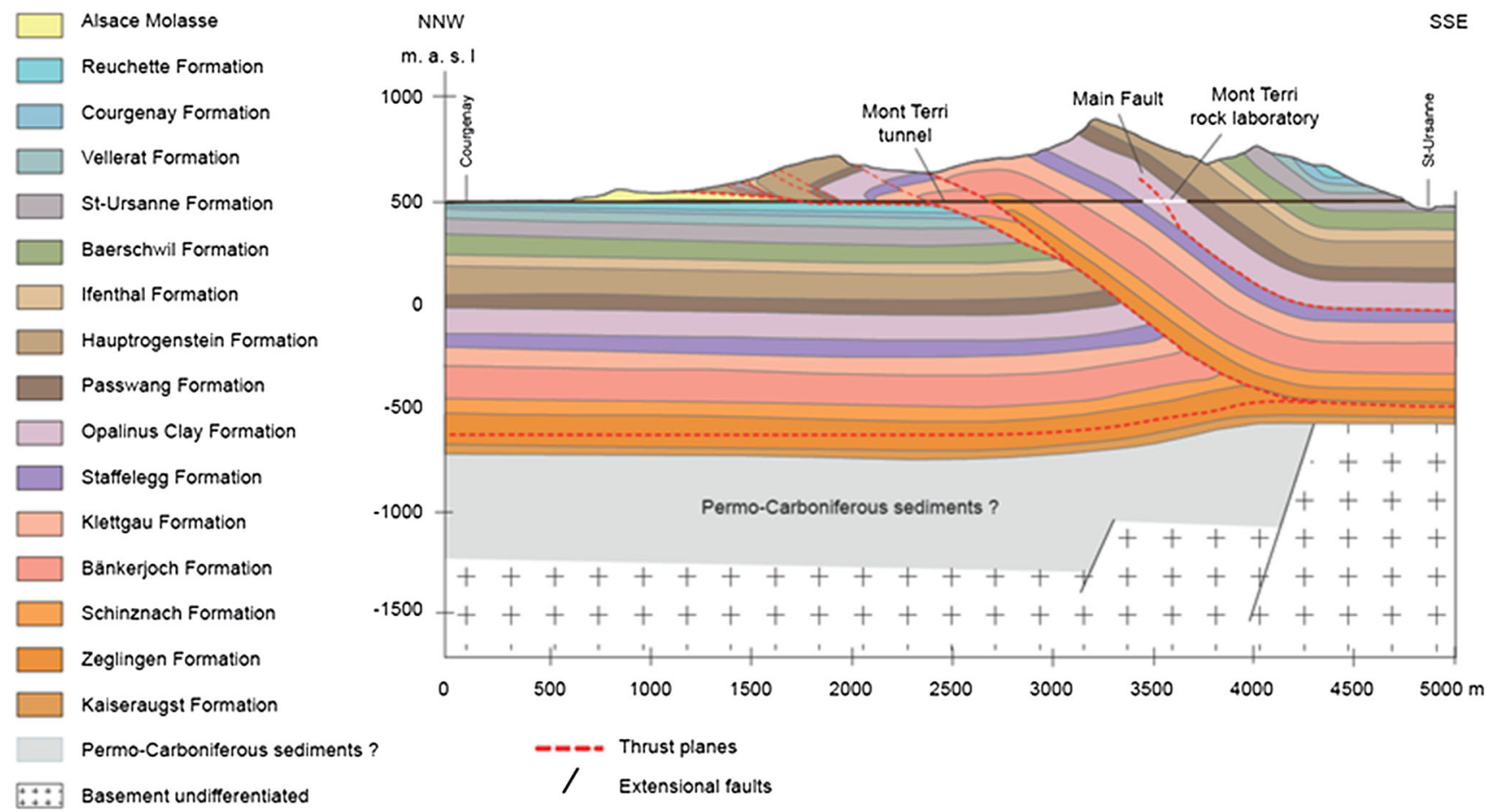

Fig. 1 Geological cross-section of the Mont Terri anticline and location of the Mont Terri rock laboratory (Nussbaum et al. 2017, this volume)

shrinkage, the excavation damaged zone (EDZ), and orthotropic material conditions. The aim of the presented work is to obtain an increased process understanding of the observed effects. Since 2006, the temporal evolution of the water content, the convergence of the niche as well as apertures of a crack were continuously measured and the derived values compared with numerical simulation results. The measurements conducted in the context of the $\mathrm{CD}$ experiment are continued in the LP-A (long-term monitoring of pore parameters) experiment. The numerical model approach considers strictly defined effects and enables the determination of significant processes.

The following article starts with a description of the experimental set-up in the niche. Additionally, the measurements are briefly summarized. After that, a numerical model approach is presented. Here, the physical effects are transferred to a mathematical description of the model. The investigated effects concern three different points: (1) the hydraulic process, (2) the mechanical process and (3) the phenomenological investigation of one single crack. The derived results are presented and compared with the measurements in the subsequent sections. Finally, the results are discussed, followed by conclusions and an outlook.

Similar aspects have been investigated in the Underground Research Laboratory in Tournemire (France) [discussed in Maßmann (2009)] and Meuse-Haute-Marne (France) (Yildizdag et al. 2014) which are also located in claystone.

Maßmann (2009) introduced hydraulic-mechanically coupled numerical simulations with the finite element code
RockFlow. Sensitivity studies point to the permeability being the significant input parameter; comparisons with various measurements are carried out (see also Maßmann et al. (2008)) and the differentiation of a fully saturated, a desaturated and a seasonally influenced desaturated zone is introduced. The measured saturation profiles in Tournemire are wide spread, indicating an inhomogeneous distribution of permeabilities which might be induced by desaturation fissures.

Yildizdag et al. (2014) investigated related effects in the context of the mine-by experiment carried out in MeuseHaute-Marne (France). He proposes different finite element models and uses the simulation tool RockFlow involving coupled hydraulic-mechanical effects, shrinkage, partial saturation, damage and sensitivity studies concerning permeability, and Young's modulus. Yildizdag et al. (2014) states that the mechanical response in the near-field could not be reproduced while the investigation of the pore pressure evolution leads to acceptable results.

Finally, the literature review indicates that the mechanical effects in indurated clay are not yet fully understood and that there exist various uncertainties concerning the measured and simulated saturation profilesespecially in the near-field of the niche. This work deals with the hydraulic-mechanically coupled simulation of the considered effects. It focuses on a relatively simple mechanical approach in combination with a complex hydraulic-mechanical coupling, with the aim of identifying significant effects. 


\section{Experimental set-up in the niche and measurements}

In-situ measurements are carried out in the EZB-niche (Fig. 2), where the claystone is not covered with shotcrete. Here, the atmospheric changes in temperature and relative humidity directly affect the wallrock. The effects which are generated due to these "open conditions" are monitored by various long-term, as well as one-time, measurements.

Long-term measurements of temperature, relative humidity and the convergence of the niche are carried out. The measurements of the relative humidity and

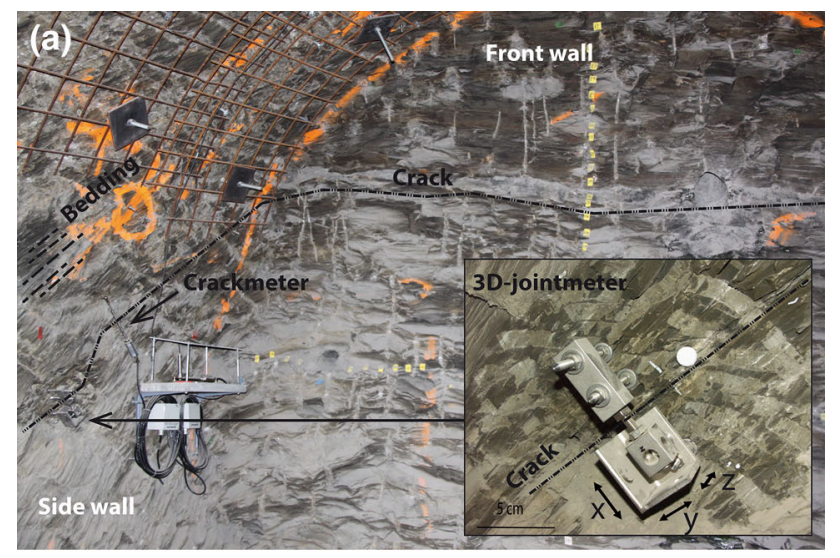

(b)

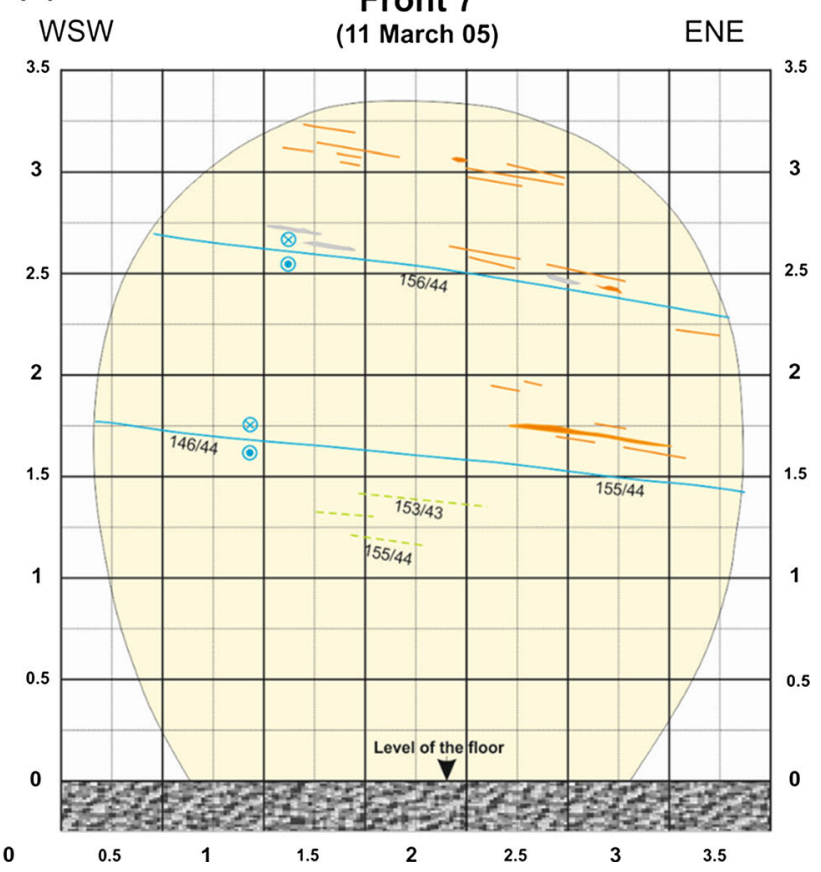

Fig. 2 The EZB-niche in the Mont Terri rock laboratory is not covered with shotcrete. Various measuring devices are installed. The upper picture indicates the location of the crackmeter and the jointmeter [taken from Möri et al. (2010)]. The lower picture is taken from Nussbaum et al. (2005) and indicates the bedding trace, as well as the location of pre-existing fractures in the wallrock of the niche temperature are presented in Fig. 3, the convergence measurements are given in Fig. 15. More information can be found in e.g. Möri et al. (2010), and Matray and Möri (2012).

The temporal evolution of the fracture apertures suggests a correlation between variations in crack aperture and the variation in the tunnel climate conditions. Consequently, the long-term crack aperture, and the associated shear displacements of selected shrinkage cracks at a bedding-parallel plane in the rock matrix, have been measured by a crackmeter and a 3D- jointmeter (Girardin and Nussbaum 2006; Jaeggi and Gisiger 2012). The crackmeter measures its own deformation and is located perpendicular to an existing crack. The time series is acquired automatically using an independent data acquisition system (DAS). The jointmeter measures relative movements in three directions at two different measurement blocks located on two sides of a selected shrinkage crack. The displacements are manually acquired every $5 / 7$ days.

Additional laboratory experiments with drill cores under controlled initial and boundary conditions are summarized in Matray and Möri (2012). The investigations determine profiles of the porosity, the gravimetric and volumetric water content, the degree of saturation, and the grain density over the length of the $3.28 \mathrm{~m} \mathrm{BCD}-3$ borehole drilled in June 2012. The results indicate characteristic values for the undisturbed rock, as well as modified values resulting from various kinds of rock damage: such as shrinkage cracks, natural fractures, or fractures induced by excavation and/or handling.

The long-term measurements, as well as laboratory investigations, started in 2006. They are supplemented by the installation of a so-called TDR probe (Time Domain Reflectometry) in the BCD-3 borehole in 2012. This modular packer system consists of five modules, each

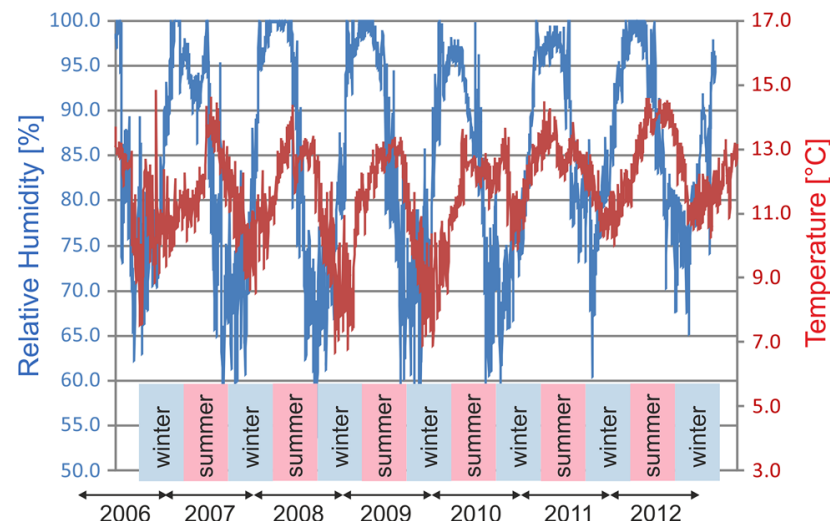

Fig. 3 Measurements of relative humidity (blue) and air temperature (red) in the EZB-niche. The measurements are presented for a time period of 6 years, and indicate the seasonal oscillations of relative humidity and temperature 
containing a TDR sensor located behind a latex rubber cover to avoid water intrusion. This TDR probe and related measurements produce profiles of matrix saturation, swelling and pore-water pressures from the niche surface towards the saturated rock matrix. Petrophysical and volumetric water content probe results and a discussion of the results are presented in Matray and Möri (2012) and Matray and Bailly (2014).

Additional measurements of the water content, as well as the convergence of the niche and the crack aperture, are depicted in Figs. 10, 11 and 19.

\section{Model approach}

\subsection{Definition of the problem}

The described experiment focuses on coupled hydraulicmechanical processes in the low permeability, orthotropic claystone formation with significant swelling and shrinkage behaviour. The flow process in the hydraulically orthotropic claystone is simulated using Darcýs law modified for unsaturated media, and a two-phase flow model simplified by the Richard's approach. The mechanical behaviour is described by transversal isotropic, linear elasticity.

The presented model focuses on the effects resulting from the contact of the claystone with the seasonally varying air humidity - neglecting effects induced directly by the excavation. It can be assumed that the excavation of the niche in the claystone with nearly horizontal bedding plane and an orthotropic initial stress field leads to a decrease of the pore volume in some distance sidewards the niche. This results in an increase of pore pressures. The opposite effect might appear at the top and bottom combined with a decrease of pore pressures. These effects have been investigated in Maßmann (2009) amongst others. However, there exist no pressure measurements that could confirm these assumptions-but desaturation in the horizontal direction is definitely indicated. It is assumed that the effect of desaturation dominates the evolution of the desaturated area.

The seasonal change of desaturation and resaturation in the Opalinus Clay implies shrinkage and swelling behaviour. This effect is incorporated in the model by an isotropic, linear swelling model, proposed by Rutqvist et al. (2001). Information about the swelling behaviour of the claystone can be found in Bock (2000) and Martin and Lanyon (2003). A general overview of the presented coupled hydraulic-mechanical model is given in Fig. 4. The $\mathrm{HM}$ coupling effects are considered using the Biot constant $\alpha$ and the Bishop coefficient $\chi$, reducing the effective stress approach to saturated conditions only. The Bishop coefficient is given by: $\chi= \begin{cases}0, & \text { if } S<1 \\ 1, & \text { else }\end{cases}$

This leads to the following formulation of the mechanical problem:

$\nabla \cdot\left(\boldsymbol{\sigma}-\alpha \chi\left(p-p_{0}\right) \mathbf{I}-S p_{s w, \max } \mathbf{I}\right)=0$

where the effective stress tensor $\boldsymbol{\sigma}$, the water pressure $\mathrm{p}$, the initial water pressure $\mathrm{p}_{0}$, the identity tensor $\mathbf{I}$, the water saturation $S$, and the maximal swelling pressure $\mathrm{p}_{\mathrm{sw}, \max }$.

The formulation of the hydraulic problem is given by:

$\nabla \cdot \mathbf{q}+n \frac{\partial S}{\partial t}+S \alpha \nabla \cdot \frac{\partial \mathbf{u}}{\partial t}+S_{p} \frac{\partial p}{\partial t}=0$

with: the fluxes due to Darcýs law $\mathbf{q}$, the porosity n, the time $t$, the deformation vector $\mathbf{u}$, and the storage term due to pressure changes $S_{p}$.

This model approach implies that classical Terzaghi coupling effects are restricted to the fully saturated case. For the unsaturated case, the coupling is mainly caused by the swelling and shrinkage behaviour. Gravity and the process of excavation are not incorporated in the presented model.

\subsection{Model set-up}

The coupled simulation is carried out with the finite element code OpenGeoSys (OGS). Further information concerning OGS can be found in e.g. Kolditz (2002), Wang et al. (2009), Kolditz et al. (2012b), Wang et al. (2013), and Kolditz et al. (2012a). The model set-up is performed for a 2D-model with plane strain conditions, representing a vertical slice of the niche. The model domain has an extent of $20 \mathrm{~m}$ times $20 \mathrm{~m}$ and is presented in Fig. 5. The modelled area is divided into a domain that represents the EDZ and a zone which is characterized by intact Opalinus Clay. Both areas are depicted in Fig. 6. The EDZ is assumed to have an extent of $70 \mathrm{~cm}$ at the top and at the side walls of the niche; at the bottom it is reduced to an extent of $25 \mathrm{~cm}$. Further information about the EDZ can be found in Alheid et al. (2002), Matray and Bailly (2014), Nussbaum et al. (2005), and Yong et al. (2010). In comparison to the intact claystone (index OPA), the EDZ is assumed to have a reduced strength. Yong (2007) presents a first approximation to determine the rock mass modulus in comparison with intact rock moduli for a niche located in Mont Terri and surrounded by multiple tectonic shears. The derived reductions vary between more than 75 and $50 \%$. The model presented here focuses on the reduction of the EDZ compared to the surrounding rock mass. For this case, the following properties are assumed:

$E_{||, E D Z}=\frac{1}{2} E_{||, O P A}$ 


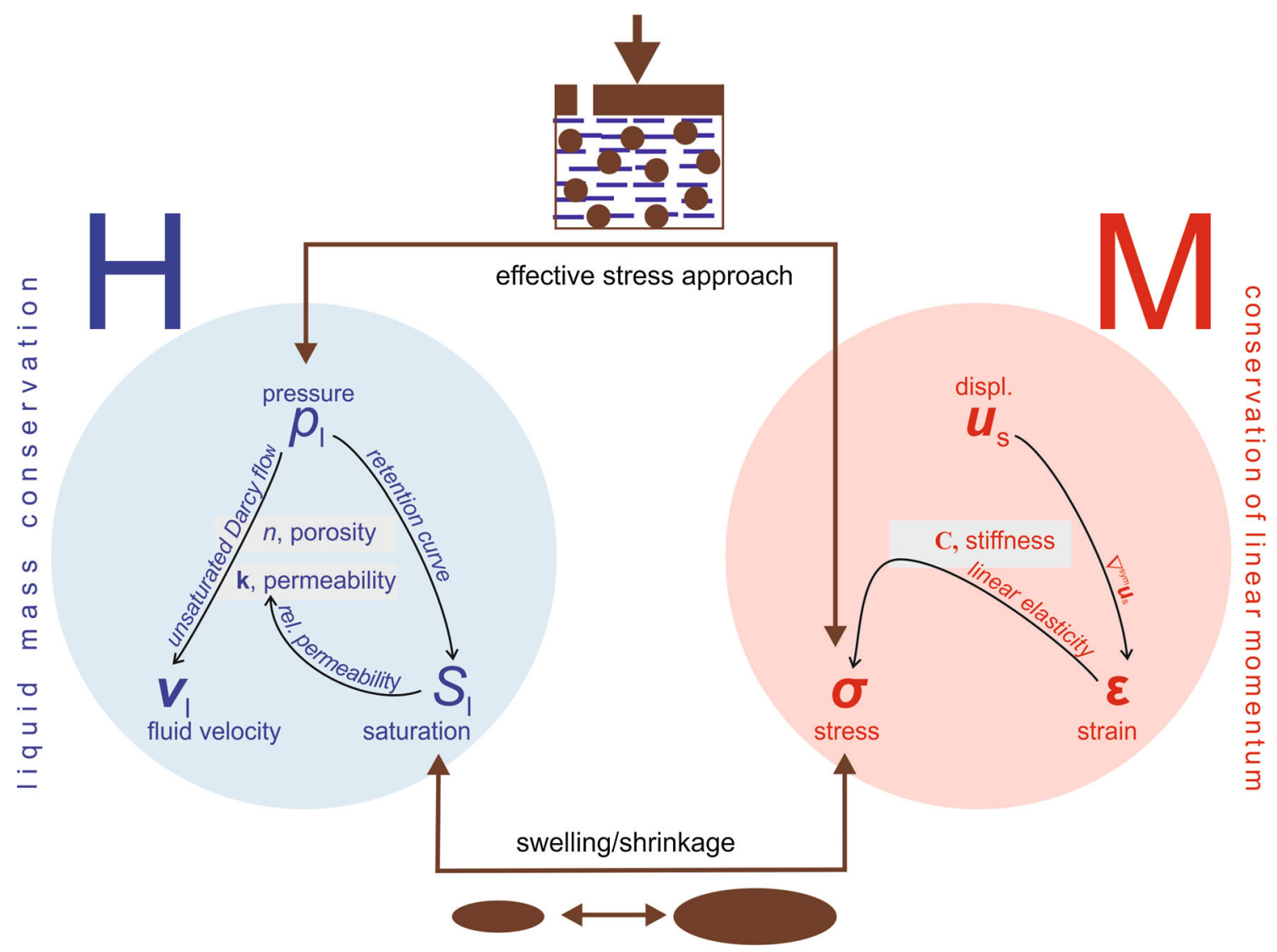

Fig. 4 Model approach for the coupled hydraulic-mechanical system [modified after Maßmann (2009)]. The simulation of the hydraulic process is based on the conservation of the liquid mass which states an interaction between pressure, fluid velocity and saturation. The mechanical process is based on the conservation of linear momentum, which incorporates interactions between stresses, strains and displacements. A coupling of both processes is implemented due to the classical Terzaghi effective stress approach, as well as a linear swelling/shrinkage model

humidity in the niche. This boundary condition is characterized by negative pore pressures (suction) and is based on the measurements as depicted in Fig. 3. As presented in Maßmann (2009), Andra (2005a) and Bond et al. (2013), the Kelvin equation is used to derive the pressure boundary condition. It is given by

$p=\frac{\rho_{l} R T}{M_{v}} \cdot \ln h_{r e l}$

with: the liquid density $\rho_{\mathrm{l}}$, the perfect gas constant $\mathrm{R}$, the absolute temperature $T$, the molecular weight of water $\mathrm{M}_{\mathrm{w}}$, and the relative humidity $\mathrm{h}_{\text {rel }}$.

The relation between capillary pressure and saturation is defined by the van Genuchten model

$S=\left[1+\left(\frac{p}{P_{0}}\right)^{1 /(1-\beta)}\right]^{-\beta}$

with: the van Genuchten fitting parameters $P_{0}$ and $R$ according to Wild et al. (2015). The relationship between the relative permeability and the saturation is defined by: 


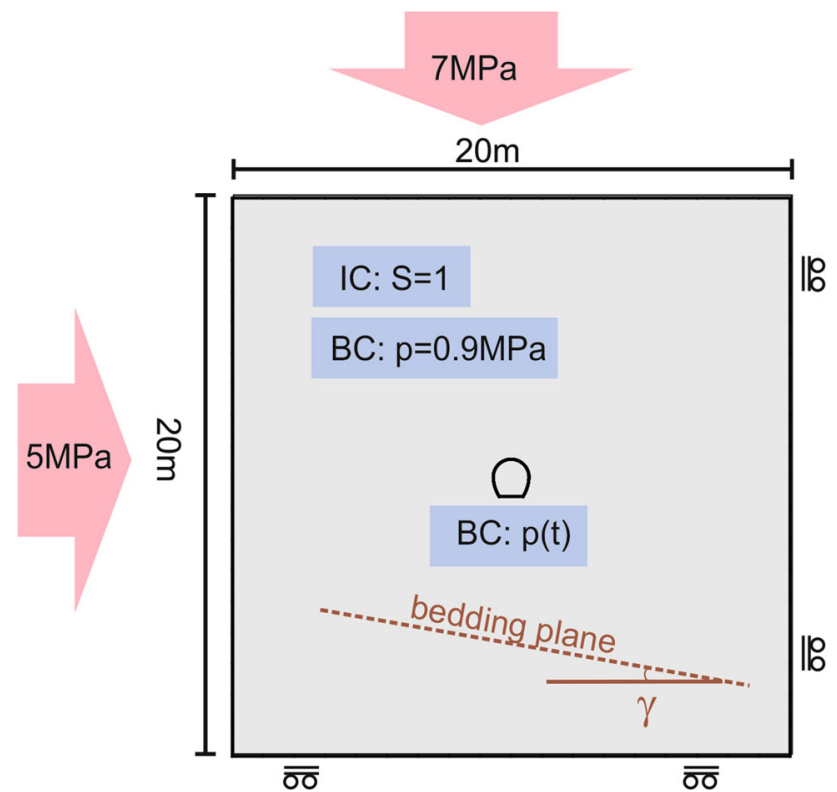

Fig. 5 Geometry and model set-up. The 2-dimensional model has an extent of 20 times $20 \mathrm{~m}$. The bedding plane in this area of the Mont Terri rock laboratory has an inclination of $10^{\circ}$. The boundaries of the numerical model are fixed in the horizontal direction at the right side, and in the vertical direction at the bottom. The far-field stresses are given by $7 \mathrm{MPa}$ in the vertical direction and $5 \mathrm{MPa}$ in the horizontal direction. Initially, the model domain is assumed to be fully saturated in the whole domain, and it is assumed to remain fully saturated at the boundaries. The pore pressure in this area is set to $900 \mathrm{kPa}$

$k_{r e l, S}=S_{e f f}^{0.5}\left[1-\left(1-S_{e f f}^{\frac{m}{m-1}}\right)^{\frac{m-1}{m}}\right]^{2}$

where the shape factor $\mathrm{m}$ and the effective saturation are given by:

$S_{\text {eff }}=\frac{S-S_{\text {res }}}{S_{\max }-S_{\text {res }}}$ with: the effective saturation $S_{\text {eff }}$, the residual saturation $S_{\text {res }}$, and the maximal saturation $S_{\max }$. The hydraulic and mechanical parameters are taken from Bock (2009), Wild et al. (2015), and Xu et al. (2014). The permeability is calibrated with respect to the measurements of the water content. All parameters are summarized in Table 1.

\section{Hydraulic results}

The proposed model represents a desaturation of the claystone due to the exposure of the wallrock to the tunnel atmosphere. While the desaturated zone increases during the cold and dry winter, there exists a temporary resaturation close to the tunnel during the warm, wet summer months. The desaturated zone for the summer, as well as the winter, is presented in Fig. 7 seven years after the excavation. The extent of the desaturated zone reaches its maximum in the direction of the bedding, and has an extent of nearly $1.4 \mathrm{~m}$ at this time.

A validation of the depicted effect is carried out by means of a comparison of measurements and simulation results concerning the temporal progression and the degree of desaturation. The desaturated zone can be divided into two parts: the seasonally influenced desaturated zone and the long-term influenced desaturated zone. In this context, the desaturated zone is defined by a saturation of less than $99.5 \%$. The seasonally influenced zone is defined by oscillations of the water content of more than $0.2 \%$-lower deviations are not mandatory connected with seasonal effects.
Fig. 6 Part of the finite element mesh incorporating the EDZ. The numerical simulation with OpenGeoSys (OGS) is carried out on a triangle mesh with an extent of 20 times $20 \mathrm{~m}$. The figure represents the central part of this mesh. The blue area represents the excavation damaged zone (EDZ), while the black parts constitute the intact claystone

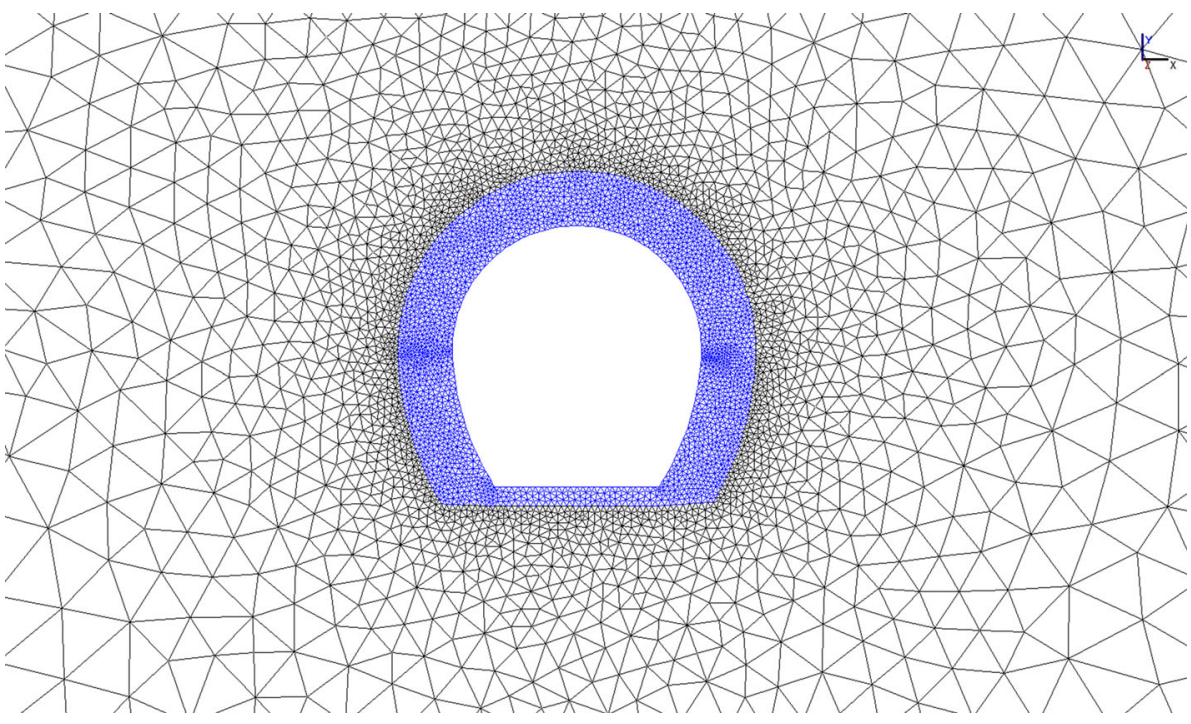


Table 1 Hydraulic and mechanical parameters which are used in the numerical model

\begin{tabular}{lll}
\hline Parameter & Value & Unit \\
\hline Angle of inclination, $\gamma$ & 10.0 & - \\
Porosity, $n$ & 0.16 & $\mathrm{~m} / \mathrm{s}$ \\
Hydraulic conductivity, $K$ & $4.0 \mathrm{e}-13$ & $\mathrm{~m}^{2}$ \\
Permeability in the plane of isotropy, $k_{\|}$ & $6.8 \mathrm{e}-20$ & $\mathrm{~m}^{2}$ \\
Permeability normal to the plane of isotropy, $k_{\perp}$ & $1.36 \mathrm{e}-20$ & $\mathrm{~kg} / \mathrm{m}^{3}$ \\
Liquid density, $\rho_{l}$ & 1000 & $\mathrm{~J} /(\mathrm{K} \mathrm{mol})$ \\
Perfect gas constant, $R$ & 8.314 & $\mathrm{~kg} / \mathrm{mol}$ \\
Molecular weight water, $M_{w}$ & 0.018 & - \\
Biot constant, $\alpha$ & 1.0 & - \\
Bishop coefficient, $\chi$ & $0.0-1.0$ & $\mathrm{~kg} / \mathrm{m}^{3}$ \\
Grain density claystone, $\rho_{s}$ & 2500 & - \\
Poisson number in the plane of isotropy, $v_{\|}$ & 0.18 & - \\
Poisson number normal to the plane of isotropy, $v_{\perp}$ & 0.16 & $\mathrm{~N} / \mathrm{m}^{2}$ \\
E in the plane of isotropy, $E_{\|}$ & $3.6 \mathrm{e} 9$ & $\mathrm{~N} / \mathrm{m}^{2}$ \\
E normal to the plane of isotropy, $E_{\perp}$ & $1.1 \mathrm{e} 9$ & $\mathrm{~N} / \mathrm{m}^{2}$ \\
G normal to the plane of isotropy, $G_{\perp}$ & $1.2 \mathrm{e} 9$ & $\mathrm{~N} / \mathrm{m}^{2}$ \\
Maximal swelling pressure, $p_{s w, \text { max }}$ & $7.0 \mathrm{e} 7$ & $\mathrm{~Pa}$ \\
Van Genuchten parameter, $P_{0}$ & $44.4 \mathrm{e} 6$ & - \\
Van Genuchten parameter, $\beta$ & 0.54 & - \\
Van Genuchten parameter, $m$ & 2 & - \\
Residual saturation, $S_{r e s}$ & 0.002 & 1.0 \\
Maximal saturation, $S_{\text {max }}$ & & - \\
& &
\end{tabular}

\subsection{Comparison of the simulation results with measurements of the TDR probe}

In summer 2012 (7 years after the excavation of the niche), a TDR probe was installed in borehole BCD-3 which is located along the horizontal line shown in Fig. 7 (bottom). Figure 8 presents measurements of the volumetric water content over a time period of nearly 4 years. These results are compared with simulated water contents which are presented over the distance away from the niche.

The measurements of the water content (Fig. 8) are presented for five locations determined by the geometry of the TDR probe. Initially, results indicate an influence of the drilling at the borewall which lead to a significant decrease of the water contents in the vicinity of the borehole. In addition, a step-like increase/decrease and a subsequent decrease/increase in the water content can be seen between January and April 2013, June 2014, and November/December 2014. These steps as well as the decrease of the water content, that can be observed since November 2015 for all five positions, are artefacts which result from technical reasons concerning the design of the TDR probe. In addition, the volumetric water content indicates-location dependent-that it is part of either the seasonally influenced desaturated zone, the desaturated zone or the saturated zone. TDR 5 is located at a distance of $0.38 \mathrm{~m}$ from the niche. The water content indicates seasonal variations with an amplitude of $0.5 \%$. This location belongs to the seasonally influenced desaturated zone. TDR 4 is located at a distance of $0.99 \mathrm{~m}$ from the niche. The volumetric water content indicates desaturated conditions but no significant seasonal influence. TDR 3, which is located at a distance of $1.61 \mathrm{~m}$ from the niche, yields similar results. For this location, the measurements indicate even lower water contents than for the location of TDR 4. TDR 2 and TDR 1 are located at distances of 2.22 and $2.83 \mathrm{~m}$ respectively from the niche. They are not characterized by seasonal influences, but by a minor saturation process. The material at these locations seems to be under nearly saturated conditions.

The simulation results presented in Fig. 9 indicate volumetric water contents between 13.4 and $13.8 \%$ at the location of TDR 5. This equals an amplitude of $0.4 \%$, and an association with the seasonally influenced zonematching the result of the measurements. Both investigation methods indicate seasonal influences at this location. Furthermore, the numerical simulation indicates that the output location of TDR 4 belongs to the long-term influenced desaturated zone-again matching the result of the measurements. The numerical simulation suggests that the location of TDR 3 belongs to the saturated zone, which does not agree with the measurements. Regarding the 

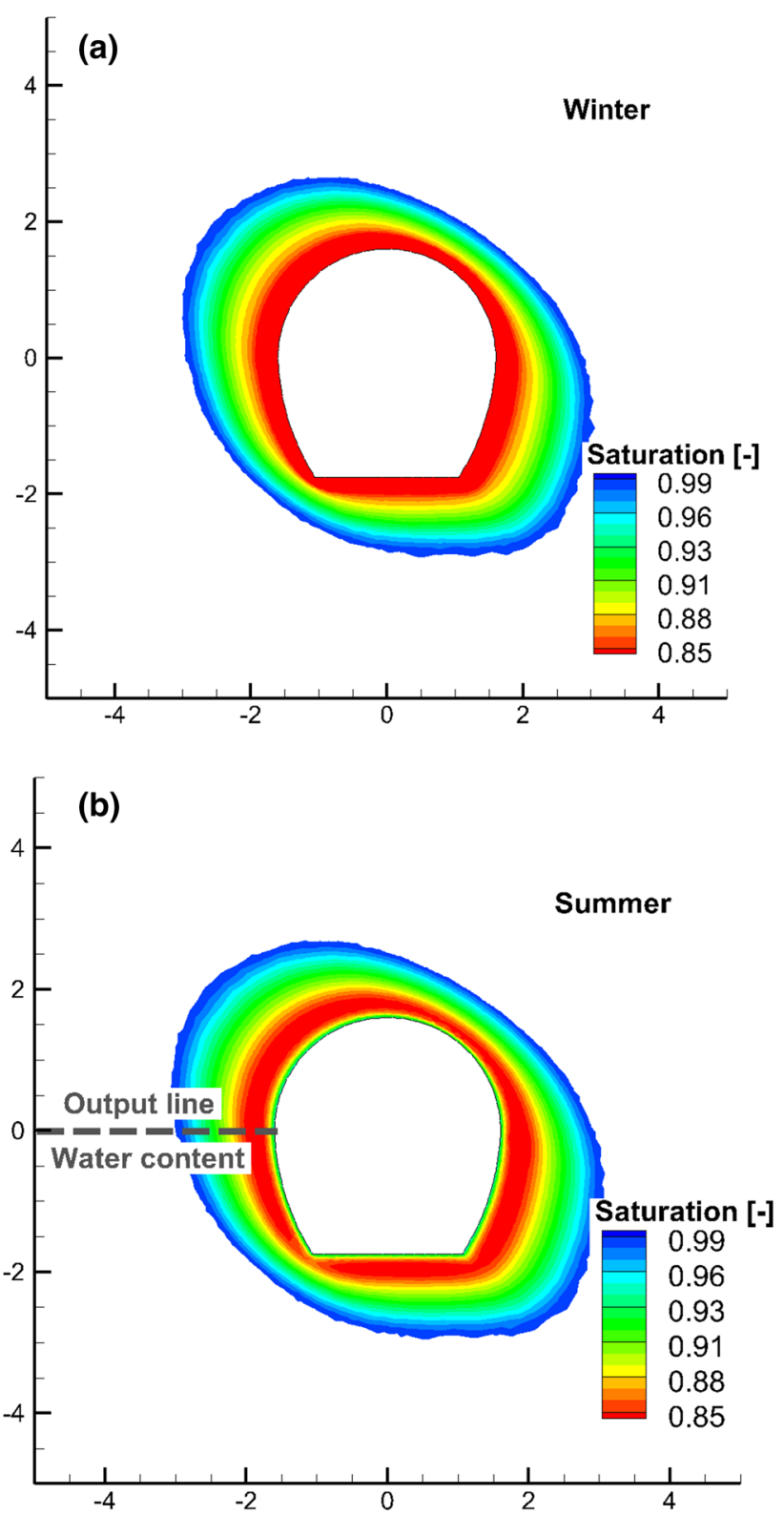

Fig. 7 Desaturated area in winter (top) and summer (bottom) after 7 years under atmospheric influence. The coloured area represents the zone where the saturation is lower than $99 \%$. The comparison of the winter and summer cases indicates a seasonal influence in the vicinity of the niche. The influence of the orthotropic material properties can be seen. Furthermore, the picture at the bottom contains the identification of the output location for the following investigations of the water content

unexpectedly low measured water contents at this location, reasons for this difference might be a heterogeneity of the claystone and/or an irregular borehole shape at this position. Please refer also to the results of the petrophysical measurements on core samples (presented in section. 4.2, Fig. 10), which also indicate heterogeneities at this location. For the locations of TDR 4 and TDR 5, both investigation methods indicate fully saturated conditions 7 years after excavation. Finally, the measured water contents are lower than the simulated ones, but the comparison of the investigation methods shows good agreement concerning the extent of the desaturated zone, the extent of the seasonally affected zone, and the seasonal oscillations of the water content, which are also presented in Table 2.

\subsection{Comparison of the simulation results with petrophysical measurements on core samples}

In combination with the drilling of borehole BCD-3, core samples were taken and investigated in the laboratory. The derived volumetric water content is presented in Fig. 10 over the distance from the niche, along the output line which is defined in Fig. 7 (right). A comparison of these measurements with simulation results for the summer and winter is depicted. The simulation indicates that the seasonally-influenced desaturated zone is characterized by the ongoing change between desaturation and resaturation, while the water content in the long-term desaturated zone undergoes only minor changes. The core samples were taken in summer, and give the summer cycle extent of the water content. The comparison of both investigation methods shows good agreement of the water content 7 years after excavation. The numerical simulation results significantly depend on the assumed permeabilities and the saturation-dependent relative permeabilities. The measurements indicate the existence of heterogeneous areas resulting in deviant behaviour. Finally, the measurements as well as the simulation indicate an extent of the desaturated zone of about $1.4 \mathrm{~m}$ after 7 years. Lower water contents which are measured at greater distances are interpreted as heterogeneities of the material. The simulation indicates an extent of the seasonally influenced zone of about $50 \mathrm{~cm}$. The results are summarized in Table 2 .

\subsection{Long-term evolution of the desaturated zone}

In this article, the comparison of measurements and simulation results is used to verify the model approach. Incorporating the model set-up, the results of a long-term simulation can also be interpreted. Here they do not incorporate damage or plastic effects, nevertheless they indicate that an equilibrium stage will hardly be reached in 15 years due to an ongoing, very low desaturation process. However, the hydraulic (please refer to Fig. 11) and mechanical (see Fig. 15) long-term results seem to converge on an equilibrium stage, and most of the convergence as well as most of the desaturated area, already develops in the first 10 years. 15 years after the excavation of the niche, the extent of the seasonally influenced desaturated zone is given as $50 \mathrm{~cm}$ (as already stated as a result after 
Fig. 8 Measured volumetric water contents over the time. The measurements represent the evolution of the water content over a time period of nearly 4 years. Initially, a decrease in water content due to the drilling of the borehole takes place. The red curve shows the water content in the vicinity of the niche and is characterized by seasonal oscillations. The pink and the green curves are located in the desaturated zone, while the output locations given by the blue lines seem to be located in nearly saturated conditions
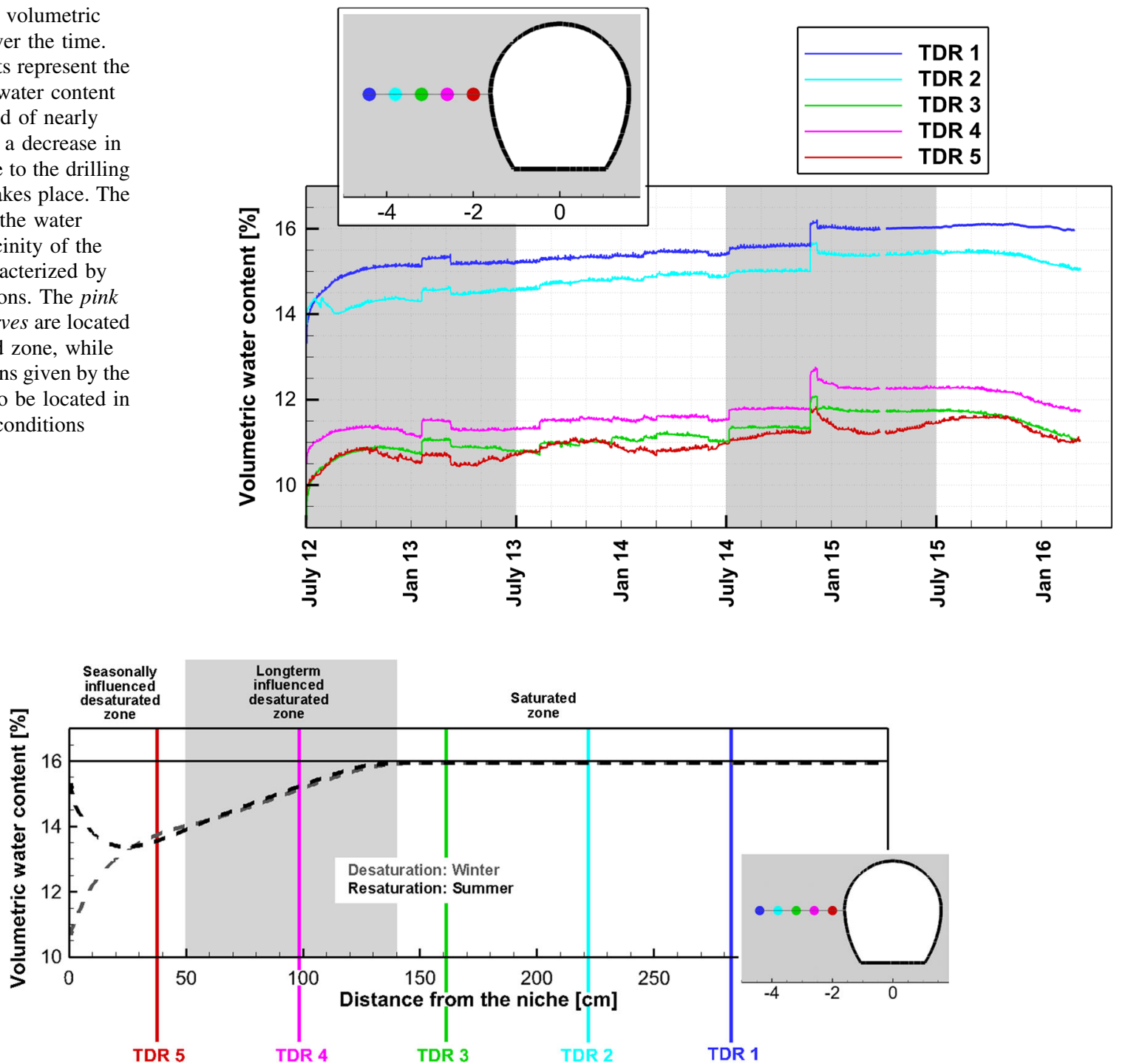

Fig. 9 Simulated water content (7 years after excavation) versus the distance from the niche for the horizontal line given in Fig. 7 (right). Lines represent the desaturation case in winter (grey) and the resaturation case in summer (black). The comparison allows for the

7 years) and the long-term desaturated zone has an extent of $2.2 \mathrm{~m}$.

\subsection{Summarizing the results}

The presented results regarding the comparison of the numerical simulation with the measurements are summarized in Table 2. Here, a classification of the different locations with respect to the saturation state is presented. It can be stated that the results concerning the extent of the desaturated zone show good agreements. Only the measurements at the location of TDR 3 indicate heterogeneous material behaviour or some kind of fractured zone, which is not considered in the homogeneous numerical model. definition of a seasonally influenced desaturated zone, a long-term influenced desaturated zone and a saturated zone. The coloured lines mark the output locations of the TDR-measurements

The results from the TDR at the drilling date do not provide any information regarding the seasonal variation, because they are not time-dependent. Consequently, the output location TDR 1 is only classified as "DZ" (desaturated zone).

\section{Mechanical results}

Concerning the mechanical processes, the desaturation implies an area of compaction due to the shrinkage of the material. The resulting stress state is given in Fig. 12 for the winter. Here, a decrease of the compressive stresses can be observed in the near-field of the niche. The related 


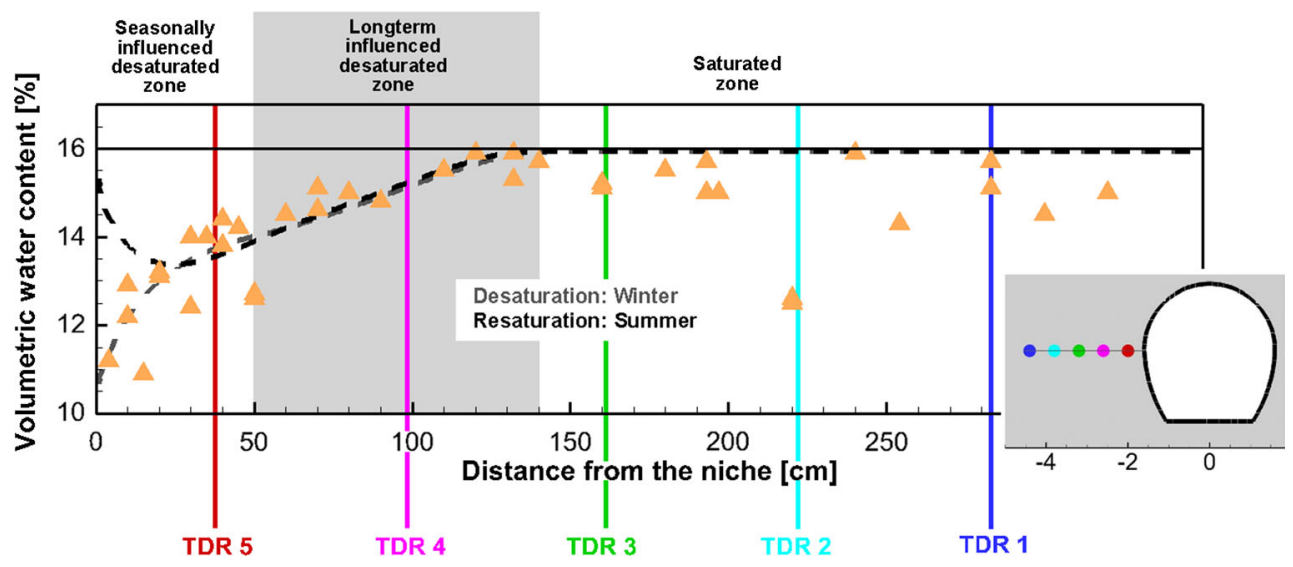

Fig. 10 Comparison of the measured and simulated water contents (7 years after excavation) versus distance from the niche for the horizontal line given in Fig. 7 (bottom). Measured values from core

samples are shown by the orange triangles. Simulated results as displayed in Fig. 9 are given for comparison

Table 2 Classification of different locations based on measurement and simulation

\begin{tabular}{llllll}
\hline Investigation method & \multicolumn{2}{l}{ Output location } & & \\
\cline { 2 - 6 } & TDR 1: $38.5 \mathrm{~cm}$ & TDR 2: $99.5 \mathrm{~cm}$ & TDR 3: 160.5 cm & TDR 4: 221.5 cm & TDR 5: 282.5 cm \\
\hline TDR probe & SIDZ & DZ & DZ & SZ & SZ \\
Core samples & DZ & DZ & DZ & SZ & SZ \\
Simulation (7 years) & SIDZ & DZ & SZ & SZ & SZ \\
Simulation (15 years) & SIDZ & DZ & DZ & DZ & SZ \\
\hline
\end{tabular}

SIDZ seasonally influenced desaturated zone, $D Z$ desaturated zone, $S Z$ saturated zone

${ }^{a}$ The investigation of the core samples does not provide any information on seasonal changes. TDR 1 lies in the desaturated zone, however it is not possible to state whether this zone is seasonally influenced

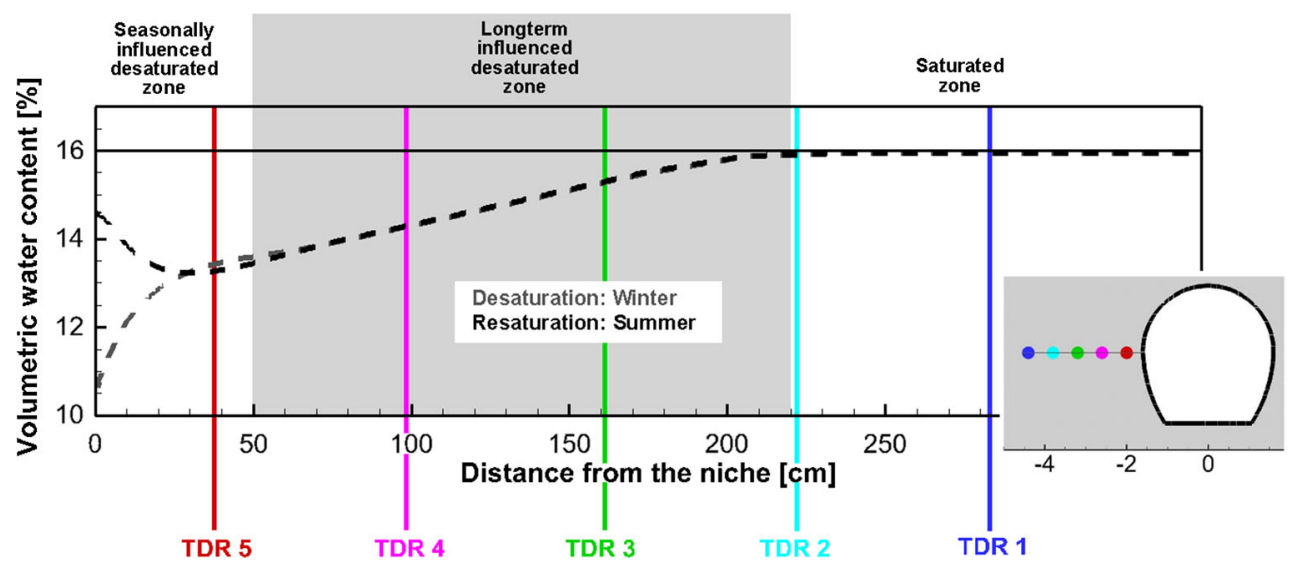

Fig. 11 Simulated water content (15 years after the excavation) versus distance from the niche for the horizontal line given in Fig. 7 (bottom). The simulation indicates an extent of the desaturated zone

vertical and horizontal displacements are given in Fig. 13 for the winter and indicate a comparatively large affected zone with movement towards the desaturated area. Due to the seasonal change between desaturation and resaturation, of approximately $2.2 \mathrm{~m}$ after 15 years. The seasonally influenced desaturated zone is quasi-stationary and has an extent of $50 \mathrm{~cm}$ 7 years after excavation in accordance with the results

the displacements at the tunnel surface may be characterized by opposite effects than the displacements at a distance of some decimetres. While movement towards the claystone can be observed at the surface of the niche, 


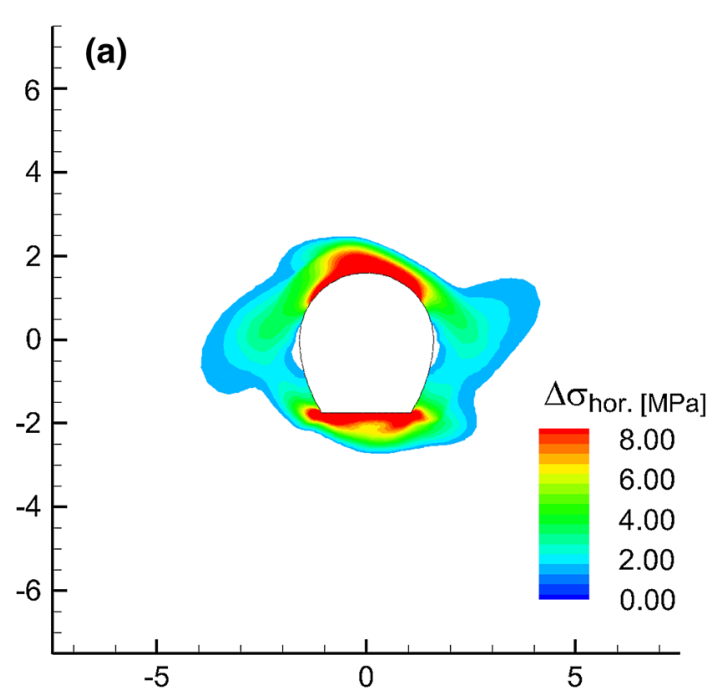

(b)

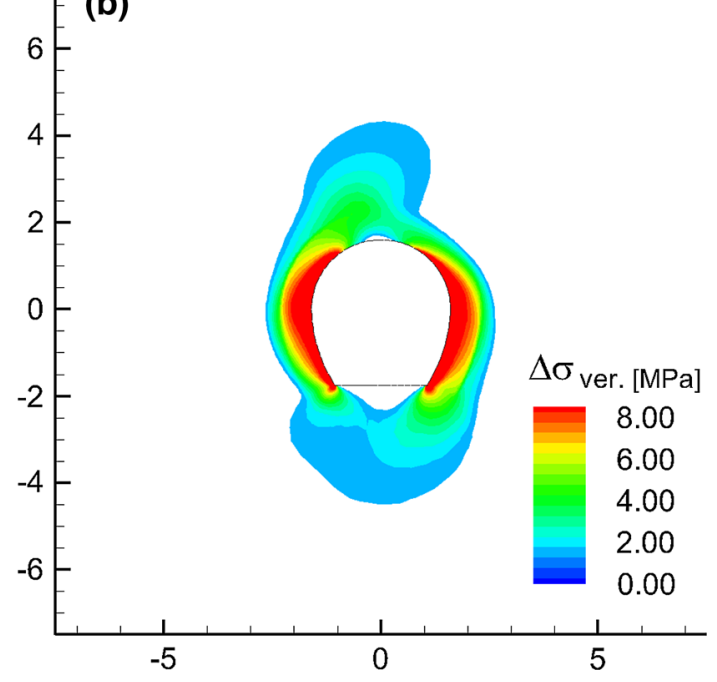

Fig. 12 Decrease in the compressive stresses after 7 years of atmospheric influence (top horizontal stresses; bottom vertical stresses) in the winter. Zones are shown where the change in the stresses is more than $1 \mathrm{MPa}$. The results in winter in this context represent the worst case. The resaturation in summer will lead to lower values

movement towards the niche can be observed at a greater distance from the tunnel. This effect significantly depends on the season. It is also presented in Fig. 14 because it leads to significant differences between the results observed at the niche surface and at locations a few $\mathrm{cm}$ away from the surface. This area is characterized by significant seasonal oscillations which are restricted to the vicinity of the niche. Measurements with regard to the anchor location ( $25 \mathrm{~cm}$ away from the niche surface) may indicate a lower impact of the seasonal variation of the climatic conditions than measurements at the niche surface.

A comparison of the numerical results with the convergence measurements of the niche is given in Fig. 15. Presented are the vertical, the horizontal and the diagonal
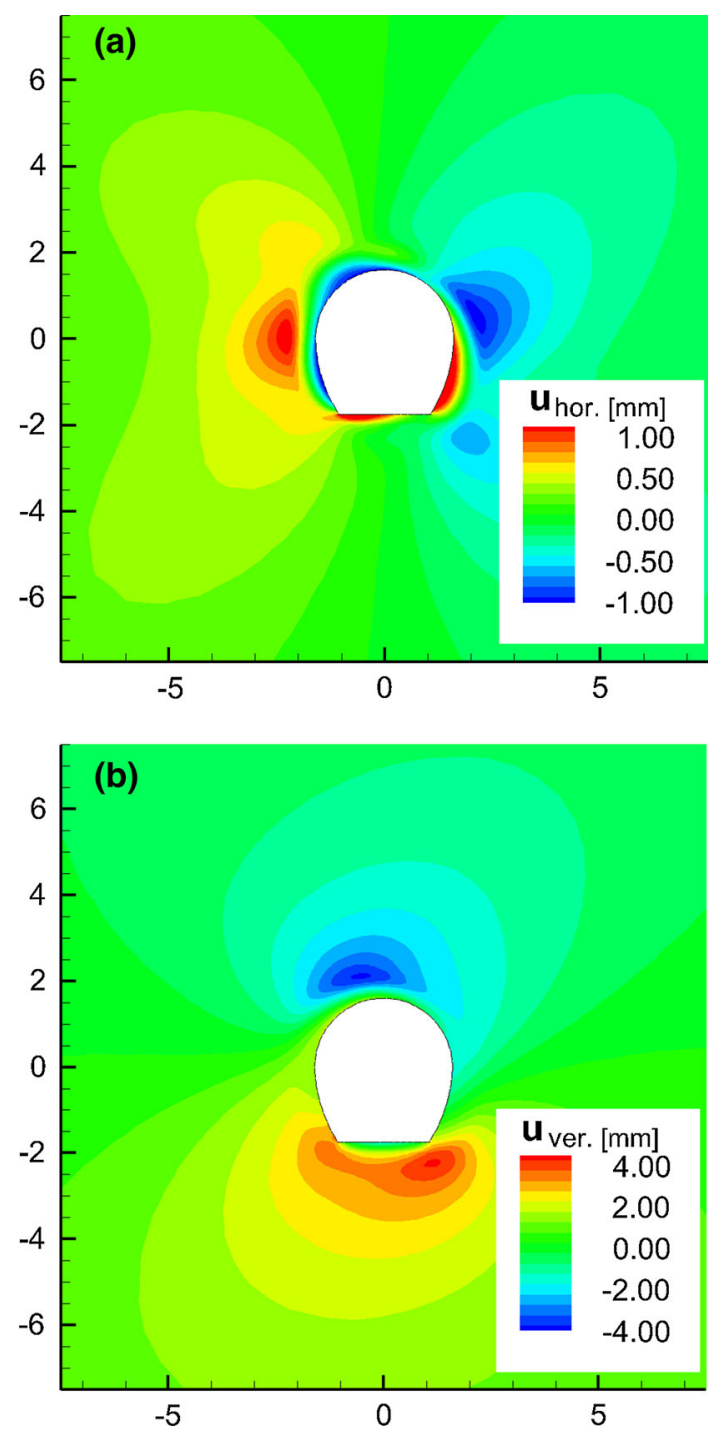

Fig. 13 Horizontal (top) and vertical (bottom) displacements after 7 years of atmospheric influence in the winter. The results indicate movements towards the niche at a distance of more than $1 \mathrm{~m}$ away from the niche. In the vicinity of the niche, these movements significantly depend on the season as is shown in Fig. 14

movement of the niche over the time. The comparison indicates good agreement of the qualitative trend. The quantitative comparison indicates an underestimation of the convergence of the niche by the numerical model. Comparative analyses indicate better results assuming a higher permeability of the claystone. Seasonal oscillations, which are indicated by the model due to the swelling and shrinkage effects, cannot be seen as clearly in the measured results. The presented convergences lead to the deformation of the niche profile as presented in Fig. 16. The measurements, as well as the numerical simulation, indicate a closure of the niche combined with a slight horizontal extension. 


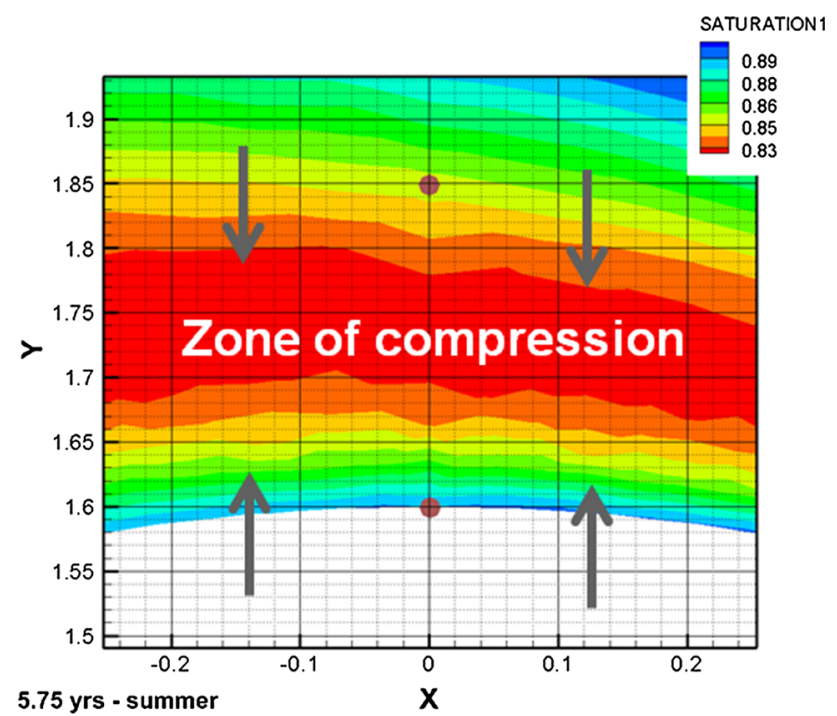

Fig. 14 Influence of the output location on the results. Due to the seasonally induced change between desaturation and resaturation, the first decimetres of claystone are characterized by manifold, seasonal effects. The saturation here-in the vicinity of the niche-varies significantly depending on the time and the location. Consequently, numerical as well as measured results depend on the output location. Results from the surface vary significantly from results e.g. at a distance of $25 \mathrm{~cm}$ away from the niche (this equals the depth of an anchor). The brown points in the figure mark the output location at the surface of the niche and at the depth of the anchor

\section{Phenomenological investigation of a single crack}

A special focus of this experiment is laid on the evolution of existing cracks at the surface of the niche. As already mentioned in Sect. 2, crackmeter as well as jointmeter

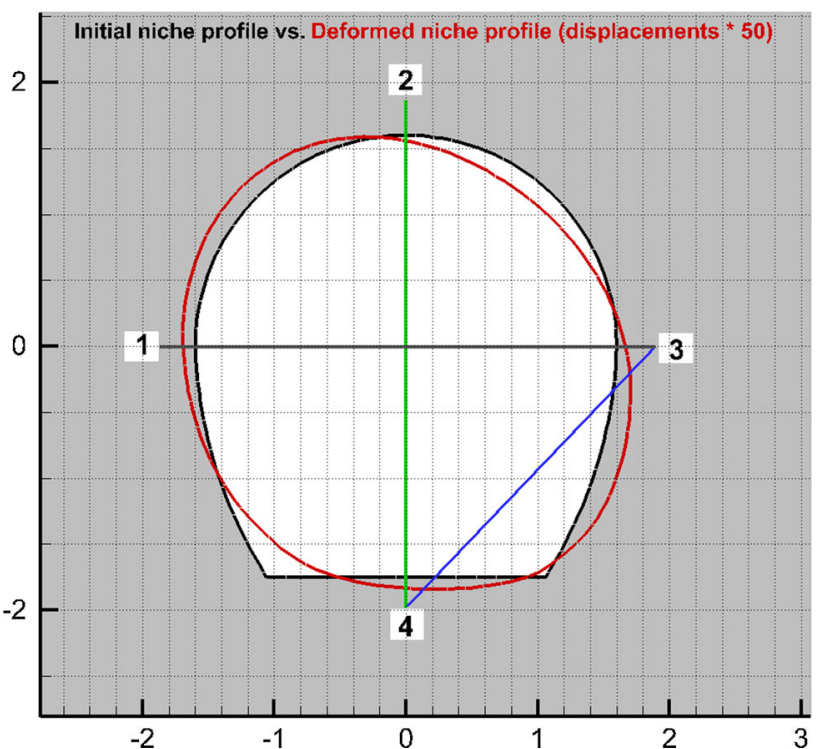

Fig. 16 The initial tunnel profile-shown by the black line in combination with the grey background - in comparison with the deformed niche which is represented by the red line. The deformed niche is scaled by a factor of 50 . The results are given for the winter 7 years after the excavation

measurements are carried out over a time period of more than 7 years. Observations concerning the tectonic and artificial (EDZ) fracture network in the vicinity of the EZB niche are presented in Nussbaum et al. (2005). To better understand the effects in the vicinity of these cracks, a first approach incorporates one single crack in the finite element model. Comparative studies were carried out with different
Fig. 15 Comparison of convergence results from measurements and simulation. Measured and simulated displacements of the presented distances are shown over time. The blue symbol (measurements) and line (simulation) present the displacements of the diagonal distance between points 3 and 4; the green symbols and line reflect displacements of the vertical line between points 2 and 4, the grey symbols and line indicate horizontal displacements between points 1 and 3. Measurements were carried out for 10 years. Keeping the differences between measurement and simulation results in mind, the numerical simulation allows for a prediction of the convergence of the niche over a longer time period

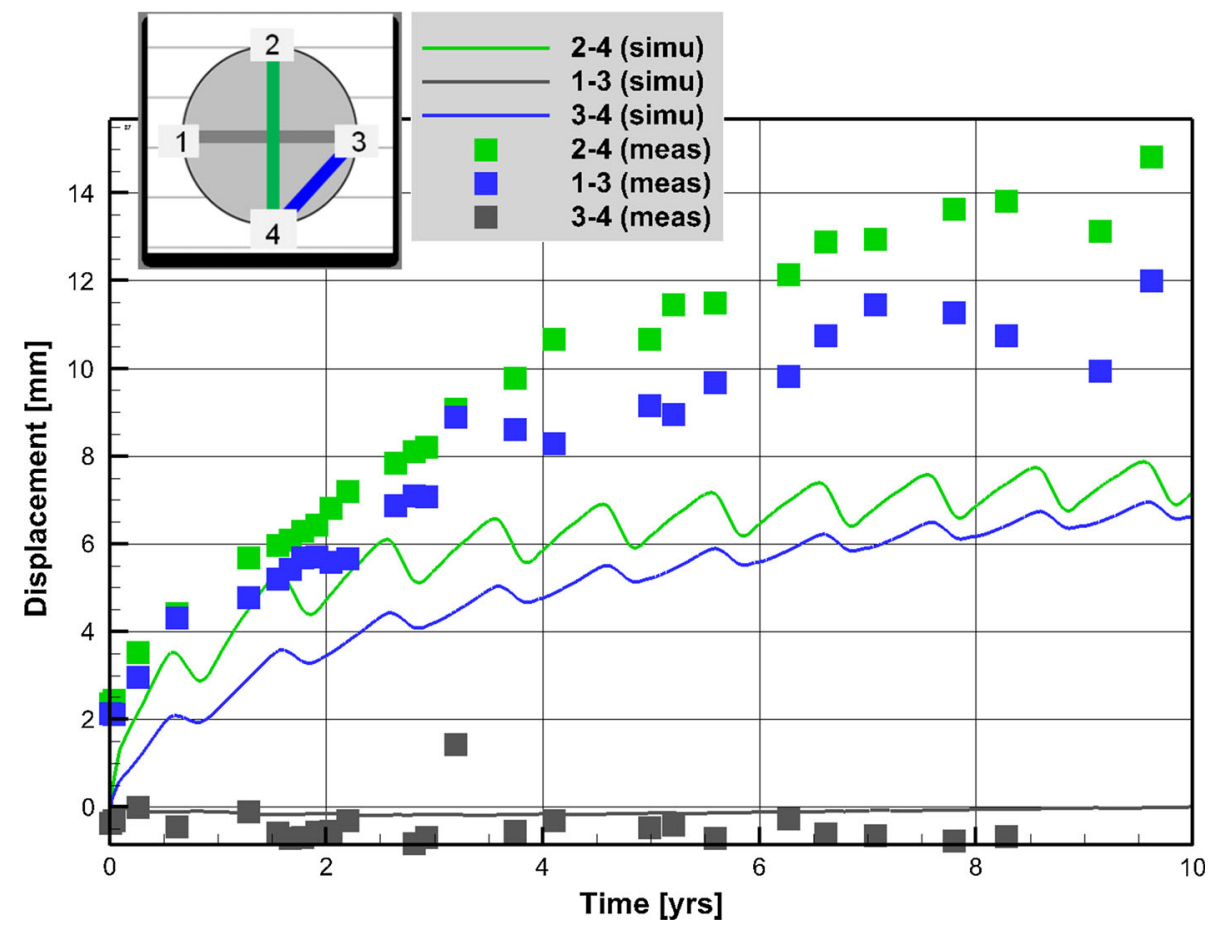


crack geometries, and do not indicate any influence of the crack geometry on the general results. The resulting mesh is presented in Fig. 17 and presents the crack which is assumed to be filled. The parameters of the filling material are supposed to be isotropic. As the significant deformations appear vertical to the bedding, the reference value for the Younǵs modulus is perpendicular to the bedding. The significant flow velocity is in the bedding direction-consequently, the reference value for the permeability is chosen in the bedding plane. The parameters of the crack are defined by a higher permeability and a lower strength than the Opalinus Clay. They are given by:

$E_{\text {crack }}=\frac{1}{10} E_{O P A, \perp}$

$k_{\text {crack }}=10 k_{O P A, \|}$

where the designation "crack" means the property of the filling material, and the designation "OPA" means the property of the intact claystone. A different factor between these parameters will influence the quantitative results but not the effect in general. In contrast to that, different effects would be observed if the crack is assumed to have a higher strength and a lower permeability than the OPA. The presented model set-up does not incorporate the EDZ. It indicates an increase of the surface of the niche due to the crack. Consequently, the same effects that can be observed at the surface of the niche are observed at the surfaces of the crack, which can be seen in Fig. 18. In the vicinity of the crack, a seasonally affected zone occurs. Due to the swelling and shrinkage of the claystone, the crack opens while the desaturation process takes place, and closes due to the resaturation of the claystone. But it has to be kept in mind that a long-term affected zone also exists. As already described in Sect. 4, this zone is characterized by a longterm desaturation process. This effect causes a shrinkage of

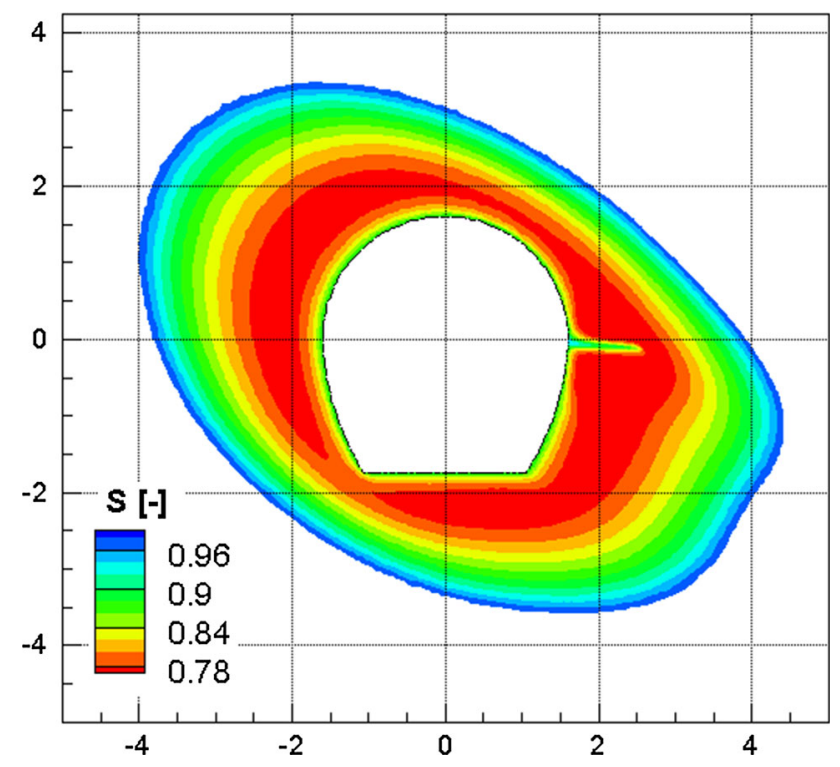

Fig. 18 The effect of resaturation (summer) and desaturation (winter) takes place in the vicinity of the niche, as well as in the vicinity of the crack. The resulting saturation for the summer 7 years after excavation is presented here

the material in the concerned area. Due to this effect, the long-term behaviour of the crack is characterized by closure of the crack. Both coexisting effects are presented schematically in Fig. 20. They can be observed in the measurements (detailed information can be found in Möri et al. (2010)) as well as in the results of the numerical simulation, and are depicted in Fig. 19. The measured relative humidity as presented in Sect. 2 is here transformed to the absolute humidity, while the displacements are taken from the crackmeter data. The changes in the saturation/absolute humidity and the aperture/displacements are given over a time period of 3 years. The seasonal oscillation of the saturation/absolute humidity leads to
Fig. 17 Part of the mesh for the phenomenological investigation of one single crack. The finite element mesh is characterized by a very fine discretization in the vicinity of the crack. The black areas represent the intact claystone, while the blue areas represent the filling material of the crack. This model does not incorporate any excavation damaged zone (EDZ)

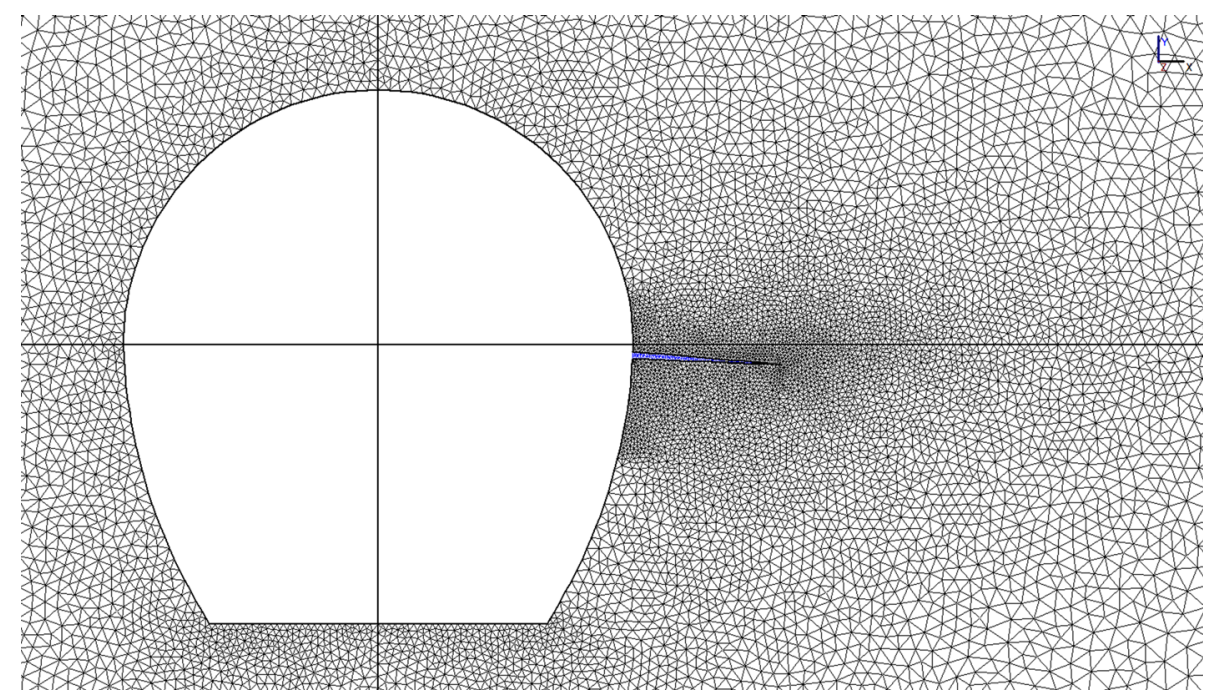


Fig. 19 The evolution of the saturation/absolute humidity and the aperture/displacements of the crack are given here over a time period of 3 years. Measurements are presented in the upper picture, simulation results in the lower picture. Both result types indicate a seasonal behaviour as well as a long-term influenced trend of the crack. The seasonally affected behaviour is characterized by opening of the crack due to desaturation of the claystone in the vicinity of the crack, and closure of the crack due to resaturation in the vicinity of the crack. The longterm trend is characterized by closure of the crack in combination with the desaturation of the nearfield of the niche. The presented results are only phenomenological results-due to the simplicity of the numerical model quantitative comparisons are not yet possible
Fig. 20 Simplified scheme of processes occurring in the claystone in the near-field and far-field of the crack due to desaturation and resaturation. As also presented in the discussion of the hydraulic results, the area is divided into two zones: the seasonally influenced zone which is the near-field of the crack and the long-term influenced zone which is the far-field of the crack. The effects due to desaturation and resaturation are presented schematically for both zones. The resulting behaviour of the crack is pointed out
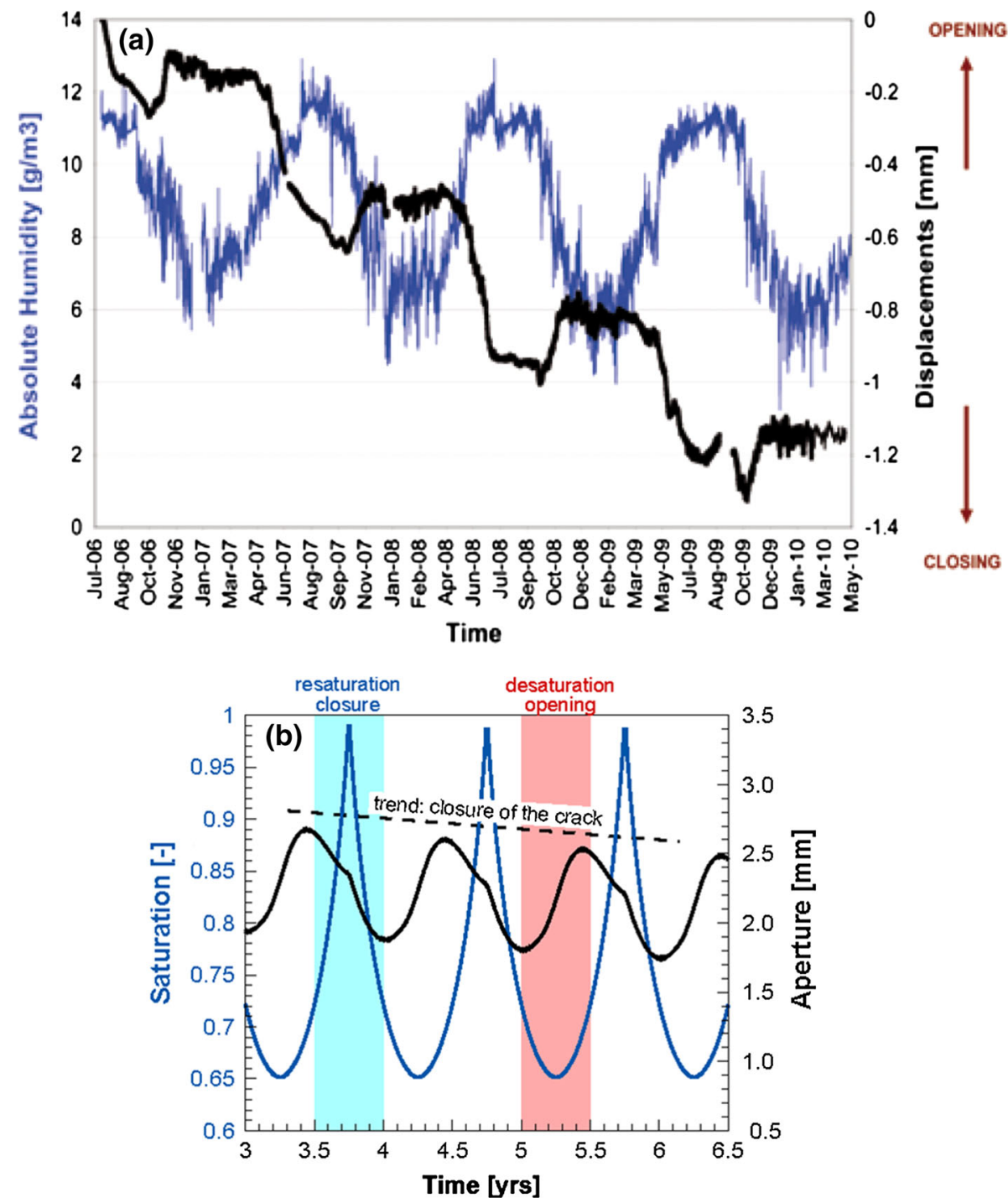

Desaturation

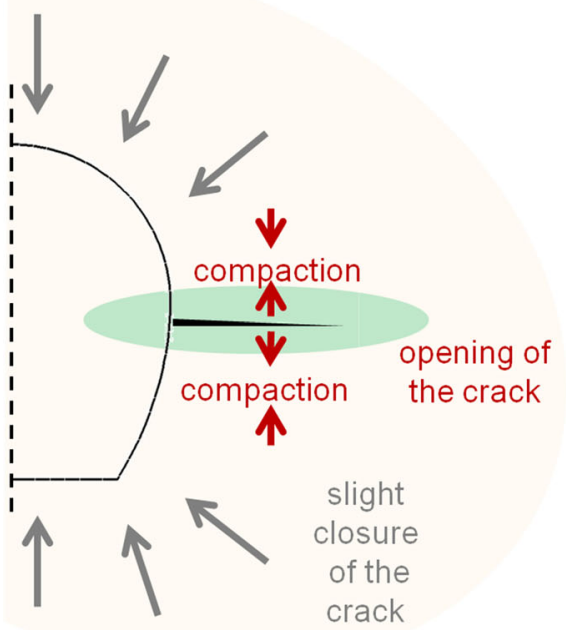

Resaturation

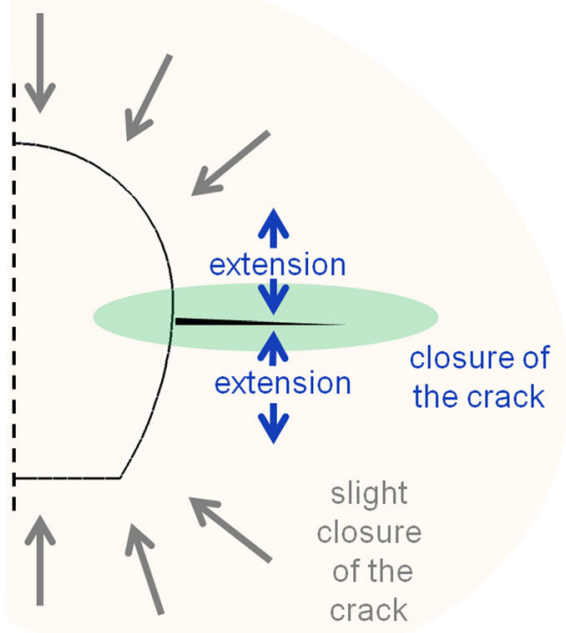


movement of the crack. While the desaturation indicates opening of the crack, the resaturation is combined with closure of the crack. Following the description of the hydraulic process in Sect. 4, this effect is called the seasonally influenced aperture of the crack. Furthermore, a long-term trend is observed in the measurements, as well as in the simulation. This trend indicates closure of the crack due to the ongoing desaturation, which leads to convergence of the niche. This effect coincides with the long-term influenced desaturated zone. The presented results reflect the described processes qualitatively.

\section{Discussion of the results}

\subsection{Hydraulic effects}

Concerning the hydraulic process, it can be stated that the desaturation and resaturation lead to three different zones in the claystone. In the vicinity of the niche, a seasonally influenced, desaturated zone develops. The extent of this zone is quasi-stationary after the first 3 years and has an extent of about $50 \mathrm{~cm}$. In addition, a long-term influenced desaturated zone arises. This zone is characterized by a desaturation which is not significantly affected by the seasonal oscillations of the atmospheric conditions in the niche. This zone has an extent of about $1.40 \mathrm{~m}$ after 7 years. The long-term simulation indicates that after 10 years the process develops slowly, because minor changes are still observed after 15 years. The extent of the desaturated zone is about $2.2 \mathrm{~m}$ at this time. The main material property affecting these results is the permeability of the claystone.

Andra (2005a) came to a similar result for the CallovoOxfordian formation at the Meuse/Haute-Marne site in France, and states that the stationary extent of the desaturated zone is 1.5 times the radius of the drift, which results in $2.48 \mathrm{~m}$ in the case of the EZB-niche. Following Andra (2005a), a permanent pattern is reached after about 10 years. Additional investigations by Andra are summarized in e.g. Andra (2005b, c, d).

Related results can be found in Maßmann (2009). He investigates hydraulic-mechanically coupled effects at the Tournemire site (France) and defined the seasonally influenced zone as the zone where the saturation varies by more than $0.01 \%$. This leads to an extent of the seasonally influenced zone of about 1-2 m around the opening. Following Maßmann (2009), the desaturated zone (saturation less than 99.9\%) strongly depends on the assumed permeability and has an extent of 2-27 m after 100 years.

Concerning the desaturated zone Alcolea et al. (2014) and Lanyon et al. (2014) state that the extent of this zone is about $2 \mathrm{~m}$ around an excavation in Opalinus Clay; this zone is found to depend significantly on the seasonal influences, and correlates with the evolution of temperature and relative humidity. The long-term effective hydraulic conductivity of the $2 \mathrm{~m}$ thick EDZ is expected to increase by approximately one order of magnitude relative to the undisturbed rock.

A comparison of the presented simulation results with the discussed temporal TDR measurements indicates good agreement concerning the water content, the extent of the desaturated zone, the extent of the seasonally affected zone, and the seasonal oscillation of the water content.

\subsection{Mechanical effects}

The mechanical effects in the vicinity of the niche are quite complex. The comparison of the numerical results with the measurements indicates qualitative agreement. The results suggest a closure of the niche combined with a slight horizontal extension, which is significantly affected by the orthotropic conditions. However, the quantitative comparison shows an underestimation of the mechanical effects. A reason for this might be the lack of a viscous material model or a damage model in the simulation, which incorporates the effect of rock strength reduction due to the seasonal oscillations. The increase in the rigidity of the argillite due to the desaturation would lead to the opposite effect. It is also not incorporated in the model, although it is proposed by Andra (2005a). The long-term simulation does not indicate an equilibrium stage after 15 years due to the ongoing but very weak desaturation process. It should not be forgotten that the results significantly depend on the output location. As many processes affect the immediate vicinity of the niche, the resulting displacements, water content, and other parameters at the surface of the niche are significantly different from the values at a distance of e.g. $25 \mathrm{~cm}$ (which is the depth of the anchors).

\subsection{Investigation of a single crack}

The phenomenological investigation of one single crack indicates the influence of seasonally changing atmospheric conditions as well as an impact of the long-term desaturation process. The simulation results match the measurements qualitatively. They indicate seasonal opening (due to the desaturation) and closure (due to the resaturation) of the crack, as well as a trend which is characterized by closure of the crack due to the long-term desaturation process, causing convergence of the niche. Both effects are illustrated in Fig. 18. As already presented in the discussion of the hydraulic results, the area is divided into the seasonally influenced zone - which is the near-field of the crack - and the long-term influenced zone, which is the far-field of the crack. The near-field is characterized by the seasonal 
change between desaturation and resaturation, which directly results in opening or closure of the crack. The same behaviour is found in the rock laboratory in Tournemire (France) (Rejeb and Cabrera 2006).

Due to the simplicity of the discussed model, quantitative statements are not yet possible. In order to obtain quantitative results, more information on the properties of the cracks is required. In addition, the numerical model has to be extended to incorporate more cracks as well as crack evolution.

Xu et al. (2014) conclude that the swelling and shrinkage behaviour of various claystones is strongly anisotropic. The deformation perpendicular to the bedding plane is higher than in the direction of the bedding, and shrinkage appears more quickly than swelling. The second statement concerning the velocity of shrinkage and swelling fits the simulation results presented here. Figure 19 clearly shows, that the opening of the crack (caused by the shrinkage effect) appears faster than the closure of the crack (caused by the swelling effect). More information about drying and cracking initiation can be found in Peron et al. (2010). Future investigations could focus on a more detailed description of the behaviour of cracks. Furthermore, the numerical model could be extended regarding plastic as well as damage effects, and regarding a more detailed description of the swelling model.

\section{Conclusions and outlook}

The seasonally induced desaturation and resaturation process, and its impact on the pore-water pressure, the convergence of the niche and the evolution of the aperture of one pre-existing crack in the wallrock of the niche are investigated. The associated measurements and simulation results, as well as the comparison of both, lead to the following conclusions which can be subdivided into three aspects concerning (1) the hydraulic processes, (2) the mechanical processes and (3) the evolution of a crack aperture.

First of all it can be stated that the relatively simple model approach enables a representation of a large number of measurements with acceptable results. This indicates that the considered effects such as swelling and shrinkage, introduced by a linear swelling model, 2-phase flow using the Richards approach, saturation-dependent material parameters, an elastic material model and orthotropic material conditions, are significant aspects concerning the discussed research question.

Focusing on the hydraulic results, the measurements, as well as the simulation, indicate the evolution of three different zones: a seasonally influenced zone, a long-term influenced zone, and a saturated zone. The seasonal changes of the atmospheric conditions in the niche induce cycles of desaturation and resaturation. This leads to a long-term desaturation process in combination with seasonal influences around the niche. The measurements and the numerical simulation show a good agreement concerning the volumetric water content of the claystone in the near-field of the niche, the extent of the desaturated zone (about $2.2 \mathrm{~m}$ after 10 years), as well as the extent (about $50 \mathrm{~cm}$ ) and amplitude of the seasonally influenced desaturated zone. Similar results can be found in the cited literature.

The mechanical results indicate a qualitative agreement concerning the trend of the convergence of the niche. Quantitatively, the simulated convergence underestimates the measured values. Furthermore, the simulation suggests significant seasonal oscillations in the convergence of the niche. This effect does not appear in the same clarity in the measurements. An improvement of the mechanical results might be achieved if plasticity, viscosity and/or damage effects are considered in the numerical model. However, the measurements, as well as the numerical simulation, indicate a convergence of the niche combined with a slight horizontal extension.

A phenomenological approach is chosen to identify processes in the vicinity of a single crack. The seasonal evolution of the crack aperture is characterized by an opening of the crack due to desaturation, and a closure of the crack due to resaturation. The long-term trend indicates a slight closure of the crack due to the convergence of the niche, which is driven by the long-term desaturation process. It can be stated that the model succeeds in representing the qualitative behaviour of the crack aperture. Consequently, the evolution of the crack aperture results from the coexistence of two effects: the seasonally induced desaturation and resaturation process in the near-field of the crack, as well as the long-term desaturation process of the niche. The impact of swelling and shrinkage on the displacements seem to play an important role in the seasonal evolution, as well as in the long-term evolution of the crack aperture.

Acknowledgements The Mont Terri Project comprises a great variety of experiments, conducted by the 14 project partners. These partners contribute technical and scientific knowledge as well as financial support. Without these partners it would not be possible to generate such a comprehensive and diverse set of field measurements as well as laboratory and numerical data to obtain an increased understanding of the complex processes in claystone. Therefore we would like to extend our sincere gratitude to all of them. The CD experiment was initiated in 2006 by swisstopo (Paul Bossart). The following partners contributed considerably to this experiment: BGR (Hans-Joachim Alheid and Kristof Schuster), ENSI (Erik Frank and Martin Herfort), IRSN (Jean-Michel Matray), Nagra (Peter Blümling and Tim Vietor), and swisstopo (A. Möri). We would like to take this opportunity to express our particular gratitude to all of them. We are also grateful to Dr. Susanne Stadler for her English proof reading and 
Dr. Peter Vogel for the fruitful discussions. Furthermore, special thanks go to Herbert Kunz for the great support concerning the preparation of the finite element mesh with his GINA software and to David Jaeggi who provided the measured data. Finally, very special thanks goes to the reviewers Dr. Alain Millard, CEA, Paris-Saclay, France and Dr. Alex Bond, Quintessa, Warrington, UK for many constructive and helpful comments and suggestions.

Open Access This article is distributed under the terms of the Creative Commons Attribution 4.0 International License (http://crea tivecommons.org/licenses/by/4.0/), which permits unrestricted use, distribution, and reproduction in any medium, provided you give appropriate credit to the original author(s) and the source, provide a link to the Creative Commons license, and indicate if changes were made.

\section{References}

Alcolea, A., Kuhlmann, U., Lanyon, G. W., \& Marschall P. (2014). Hydraulic conductance of the EDZ around underground structures of a geological repository for radioactive waste-A sensitivity study for the candidate host rocks in the proposed siting regions in Northern Switzerland. Nagra Arbeitsbericht, NAB 13-94, 101 pp. Nagra, Wettingen, Switzerland. www. nagra.ch.

Alheid, H.-J., Kruschwitz, S., Schuster, K., \& Yaramanci, U. (2002). Charakterisierung der Auflockerungszone um Strecken im Opalinuston mit seismischen und geoelektrischen Verfahren. Angewandte Geologie, 48, 48-55.

Andra. (2005a). Dossier 2005 Argile, Tome-Phenomenological evolution of a geological repository.

Andra. (2005b). Dossier 2005 Argile, synthesis-Evaluation of the feasibility of a geological repository in an argillaceous formation. France: Meuse/Haute-Marne Site.

Andra. (2005c). Dossier 2005 Argile, Tome-Savety evaluation of a geological repository.

Andra. (2005d). Dossier 2005 Argile, Tome-Architecture and management of a geological repository.

Bock, H. (2000). RA experiment rock mechanics analyses and synthesis: Data report on rock mechanics. Mont Terri Technical Report, TR 00-02, 52 pp. Federal Office of Topography (swisstopo), Wabern, Switzerland. www.mont-terri.ch.

Bock, H. (2009). RA experiment: Updated review of the rock mechanics properties of the Opalinus Clay of the Mont Terri rock laboratory based on laboratory and field testing. Mont Terri Technical Report, TR 08-04, 68 pp. Federal Office of Topography (swisstopo), Wabern, Switzerland. www.mont-terri. ch.

Bond, A., Millard, A., Nakama, S., Zhang, C., \& Garritte, B. (2013). Approaches for representing hydro-mechanical coupling between sub-surface excavations and argillaceous porous media at the ventilation experiment, Mont Terri. Journal of Rock Mechanics and Geotechnical Engineering, 5, 85-96.

Bossart, P., Bernier, F., Birkholzer, J., Bruggeman, C., Connolly, P., Dewonck, S., Fukaya, M., Herfort, M., Jensen, M., Matray, J-M., Mayor, J. C., Moeri, A., Oyama, T., Schuster, K., Shigeta, N., Vietor, T., \& Wieczorek, K. (2017). Mont Terri rock laboratory, 20 years of research: introduction, site characteristics and overview of experiments. Swiss Journal of Geosciences, 110. doi:10.1007/s00015-016-0236-1 (this issue).

Girardin, C., \& Nussbaum, C. (2006). CD experiment (cyclic deformations): Installation and procedures of measurement. Mont Terri Technical Note, TN 2006-64, 9 pp. Federal Office of
Topography (swisstopo), Wabern, Switzerland. www.mont-terri. ch.

Jaeggi, D., \& Gisiger, J. (2012). CD (cyclic deformation) experiment: Data report of Phase 17 (July 2011-June 2012). Mont Terri Technical Note, TN 2012-68, 34 pp. Federal Office of Topography (swisstopo), Wabern, Switzerland. www.mont-terri.ch.

Kolditz, O. (2002). Computational methods in environmental fluid mechanics. Berlin: Springer.

Kolditz, O., Bauer, S., Bilke, L., Böttcher, N., Delfs, J. O., Fischer, T., et al. (2012a). OpenGeoSys: An open22source initiative for numerical simulation of thermo-hydro-mechanical/chemical (THM/C) processes in porous media. Environmental Earth Siences, 67(2), 589-599.

Kolditz, O., Görke, U.-J., Shao, H., \& Wang, W. (2012b). Thermohydro-mechanical-chemical processes in fractured porous media. Berlin: Springer.

Lanyon, G. W., Martin, D., Giger, S., \& Marschall, P. (2014). Development and evolution of the Excavation Damaged Zone (EDZ) in the Opalinus Clay-A synopsis of the state of knowledge from Mont Terri, Nagra Arbeitsbericht, NAB 14-87, 204 pp. Nagra, Wettingen, Switzerland. www.nagra.ch.

Martin, C. D., \& Lanyon, G. W. (2003). Measurement of in situ stress in weak rocks at Mont Terri Rock Laboratory, Switzerland. International Journal of Rock Mechanics and Mining Sciences, 40, 1077-1088.

Maßmann, J. (2009). Modeling of excavation induced coupled hydraulic-mechanical processes in claystone. Ph.D. dissertation, Leibniz Universität Hannover, Germany, 77 pp.

Maßmann, J., Uehara, S., Rejeb, A., \& Millard, A. (2008). Investigation of desaturation in an old tunnel and new galleries at an argillaceous site. Environmental Geology, 57(6), 1337-1345.

Matray, J.-M., \& Bailly, D. (2014). LP-A experiment: Phase 20, statistical analysis of time series acquired in the EZ-B Niche and at the Main fault. Mont Terri Technical Note, TN 2014-59, $77 \mathrm{pp}$. Federal Office of Topography (swisstopo), Wabern, Switzerland. www.mont-terri.ch.

Matray, J.-M., \& Möri, A. (2012). CD (Cyclic deformation) experiment, petrophysical measurements on BCD-3 core samples from the Mont Terri rock laboratory. Mont Terri Technical Note, TN 2013-49, 27 pp. Federal Office of Topography (swisstopo), Wabern, Switzerland. www.mont-terri.ch.

Möri, A., Bossart, P., Matray, J.-M., Frank, E., Fatmi, H., \& Ababou, R. (2010). Mont Terri Project, Cyclic deformations in the Opalinus Clay. In Proceedings of the international meeting of clay in natural and engineered barriers for radioactive waste confinements, Nantes (pp. 103-124).

Nussbaum, C., Bossart, P., von Rütte, J., Meier, O., \& Badertscher, N. (2005). EZ-B experiment: Small-scale mapping of tectonic and artificial (EDZ) fractures of the EZ-B niche. Mont Terri Technical Note, TN 2005-30rev, 24 pp. Federal Office of Topography (swisstopo), Wabern, Switzerland. www.montterri.ch.

Nussbaum, C., Kloppenburg, A., Caer, T., \& Bossart, P. (2017). Tectonic evolution around the Mont Terri rock laboratory, northwestern Swiss Jura: constraints from kinematic forward modelling. Swiss Journal of Geosciences, 110. doi:10.1007/ s00015-016-0248-x (this issue).

Peron, H., Eichenberger, J., Laloui, L., \& Salager, S. (2010). Modelling of drying and cracking initiation in a gallery excavated in shale. European Rock Mechanics SymposiumEUROCK 2010, pp. 771-774. International Society for Rock Mechanics.

Rejeb, A., \& Cabrera, J. (2006). Time-dependent evolution of the excavation damaged zone in the argillaceous Tournemire site (France). In The GeoProc international conference on coupled 
THMC processes in geosystems: fundamentals, modelling, experiments and applications (invited lecture) (pp. 22-25).

Rutqvist, J., Börgesson, L., Chijimatsu, M., Kobayashi, A., Jing, L., Nguyen, T. S., et al. (2001). Thermohydromechanics of partially saturated geological media: Governing equations and formulation of four finite element models. Rock Mechanics and Mining Sciences, 38, 105-127.

Wang, Q., Cui, Y.-J., Tang, A.-M., Barnichon, J.-D., Saba, S., \& Ye, W.-M. (2013). Hydraulic conductivity and microstructure changes of compacted bentonite/sand mixture during hydration. Engineering Geology, 164, 67-76.

Wang, W., Kosakowski, G., \& Kolditz, O. (2009). A parallel finite element scheme for thermo-hydro-mechanical (THM) coupled problems in porous media. Computers \& Geosciences, 35(8), $1631-1641$.

Wild, K. M., Wymann, L. P., Zimmer, S., Thoeny, R., \& Amann, F. (2015). Water retention characteristics and state-dependent mechanical and petro-physical properties of clay shale. Rock Mechanics and Rock Engineering, 48, 427-439.

Xu, W.J., Shao, H., Hesser, J., \& Kolditz, O. (2014). Numerical modelling of moisture controlled laboratory swelling/shrinkage experiments on argillaceous rocks. In: S. Norris, J. Bruno, M. Cathelineau, P. Delage, C, Fairhurst, E.C. Gaucher, et al. (Eds.), Clays in natural and engineered barriers for radioactive waste confinement (pp. 359-366). Geological Society London Special Publication.

Yildizdag, K., Shao, H., Hesser, J., Noiret, A., \& Sönnke, J. (2014). Coupled hydromechanical modelling of the mine-by experiment at Meuse-Haute-Marne underground rock laboratory France. In: S. Norris, J. Bruno, M. Cathelineau, P. Delage, C, Fairhurst, E. C. Gaucher, et al. (Eds.), Clays in natural and engineered barriers for radioactive waste confinement (pp. 265-278). Geological Society London Special Publication.

Yong, S. (2007). A three-dimensional analysis of excavation-induced perturbations in the Opalinus Clay at the Mont Terri rock laboratory. Ph.D. dissertation, Swiss Federal Institute of Technology in Zurich (ETH Zurich), Zurich, Switzerland, 167 pp.

Yong, S., Kaiser, P. K., \& Loew, S. (2010). Influence of tectonic shears on tunnel-induced fracturing. International Journal of Rock Mechanics and Mining Sciences, 47, 894-907. 